\title{
Mechanical behaviour of bitumen emulsion-cement composites across the structural transition of the co-binder system
}

\author{
Miomir Miljković (Corresponding author) \\ University of Niš, Faculty of Civil Engineering and Architecture \\ Aleksandra Medvedeva 14, 18000 Niš, Serbia \\ Empa, Swiss Federal Laboratories for Materials Science and Technology \\ Überlandstrasse 129, 8600 Dübendorf, Switzerland \\ Email: miomir.miljkovic@outlook.com \\ Telephone: +381691016040 \\ Lily Poulikakos and Fabio Piemontese \\ Empa, Swiss Federal Laboratories for Materials Science and Technology \\ Überlandstrasse 129, 8600 Dübendorf, Switzerland

\section{Mahdieh Shakoorioskooie and Pietro Lura} \\ Empa, Swiss Federal Laboratories for Materials Science and Technology \\ Überlandstrasse 129, 8600 Dübendorf, Switzerland \\ ETH Zürich, Institute for Building Materials \\ Stefano-Franscini-Platz 3, 8093 Zürich, Switzerland
}

\begin{abstract}
The aim of this research was to understand the dependence of the mechanical behaviour of bitumen emulsion-cement composites on the structural transition of the co-binder system. The experimental programme mainly consisted of cyclic indirect tensile testing at a range of temperatures and frequencies, integrated by X-ray microtomography. The results showed the existence of a critical composition of the co-binder system at the bitumen to cement ratio between 1 and 2 at which the mechanical behaviour transformed from cement-dominated to bitumen-dominated. This was caused by both the percolation of the bituminous phase and the pore space, and the volume contraction of the co-binder system. However, this critical composition did not directly match with the percolation of the phases on the length scale of the mesostructure, but likely corresponded with the volumetric content of all elastic phases, with the aggregate playing a fundamental role.
\end{abstract}

Keywords: bitumen emulsion-cement composites; multiphase material; stiffness modulus; phase angle; X-ray tomography; percolation threshold

This document is the accepted manuscript version of the following article:

Miljković, M., Poulikakos, L., Piemontese, F., Shakoorioskooie, M., \& Lura, P. (2019). Mechanical behaviour of bitumen emulsion-cement composites across the structural transition of the co-binder system. Construction and Building Materials, 215, 217-232. 
The composites of bitumen emulsion and cement applied for structural layers of road pavements are heterogeneous materials consisting of four phases: bitumen emulsion and cement, as binders, mineral aggregate as a granular skeleton, and pore space. These four phases have substantially different physical properties and well-defined interfaces.

The use of bitumen emulsion-based materials instead of conventional hot asphalt eliminates numerous environmental risks during the construction of a pavement layer, and significantly decreases energy consumption and $\mathrm{CO}_{2}$ emissions. Bitumen is a highly viscous, amorphous, hydrophobic hydrocarbon material with a typical time and temperature-dependent mechanical behaviour. To decrease its originally high viscosity at ambient temperature, which is necessary for the mixing with aggregate, bitumen is dispersed in water in the presence of emulsifier, mostly cationic, thus producing a bitumen emulsion with droplet size typically ranging from 1 to $10 \mu \mathrm{m}[1,2,3]$. In contact with cement and aggregate, cationic emulsions are destabilised by changes in $\mathrm{pH}$ caused by release of cations at very different rates from these mineral constituents $[2,4,5,6,7]$. Consequentially, the cationic emulsions break and the bitumen droplets flocculate, coalesce, and then form a bitumen film whose morphology is determined by the mechanism and kinetics of destabilisation of emulsion $[2,8,9,10,11,12,13]$. All these physico-chemical processes determine the typical time dependence of the properties of bitumen emulsion-based materials. This temporal evolution is on the contrary absent in conventional asphalt.

In contrast to bitumen, cement is a mineral binder which hardens in a chemical reaction with water creating hydration products with a rigid structure. When cement is mixed with bitumen emulsion, the breaking of the emulsion is accelerated, and part of the water becomes chemically and physically bound in the hydration products. The water released by the emulsion wets the hydrophilic phases including unhydrated cement, hydration products, filler (in asphalt, all mineral particles smaller than $63 \mu \mathrm{m}$ ), and the rest of the aggregate (all larger mineral particles) and is held by capillary forces in the small pores. Because of the exposure to the environment, the water progressively migrates out through the pore space $[14,15]$.

Previous research [16] identified a significant effect of the emulsifier on the mechanical properties, likely resulting from its influence on the hydration kinetics of cement, rheology of 
emulsion and bitumen, and binding of water. The emulsifier and its interaction with cement controls the stability of the emulsion and the formation of the bituminous film [17]. By reducing the surface tension, the emulsifier influences the viscosity of the emulsion [18] and thus it improves the rheological properties and the workability of the mixture [19, 20, 21, 22]. Depending on its type $[23,24]$ it can either accelerate or decelerate the hydration kinetics [16, $25,26]$ and the resulting microstructure $[27,28]$. Therefore, the emulsifier was recognised as a key factor for understanding the overall behaviour of bitumen emulsion-cement composites.

The residual bitumen, cement hydrates, and aggregate play a dominant role in the mechanical behaviour of these multiphase systems. In these systems, the aggregate can be considered as the inert skeleton, since it is rigid, independent from loading time and temperature, and temporally invariable. The main emphasis for understanding the resulting mechanical behaviour, especially their temporal change [29] is, therefore, on the interactions in the twophase system of bituminous and cementitious binder, hypothesised to be acting as a co-binder. This perspective is analogous to the model systems of bitumen-filler mastic used in conventional bituminous materials [30, 31, 32], however, with much higher degree of complexity, as the intrinsic mechanical properties of these two co-binders are radically different. In this regard, bitumen is a viscoelastic rheodictic material characterised by time and temperature-dependent mechanical behaviour. On the contrary, cement hydrates are elastic and brittle, with time-dependent deformations (shrinkage and creep) negligible compared to those of bitumen.

In principle, depending on the concentrations and the interconnectivity of the co-binders as two individual phases, these systems can show widely different microstructures that manifest themselves in widely different mechanical behaviour. By representing the co-binders as a general two-dimensional system of overlapping particles, as shown in Figure 1, at low concentration of one of the co-binders, that phase is a dispersed disconnected phase (Figure 1a). However, above the critical value (called the percolation threshold), that phase becomes connected [33] (Figure 1b). Such a transformation in the phase geometry [34] of the bitumen emulsion-cement composite results in mechanical properties shifting from bitumen-dominated to cement-dominated. Thus, at the level of co-binders with low relative concentrations of cement, they may form a two-phase suspension, with the bituminous binder as continuous phase and the cementitious phase as rigid inclusions embedded in the matrix [35]. At the other end, at low relative concentrations of bitumen, the cementitious phase forms the continuous 
matrix with discrete bituminous inclusions. In the intermediate case, more complex microstructures can form depending on the bitumen to cement ratio $(b / c)$, likely resulting in both phases percolated at the same time. However, the presence of large pores (above roughly $200 \mu \mathrm{m})$ and particles of mineral filler further complicates the microstructure. Therefore, it is hypothesised that, when the bitumen content is increased, the transition of the mechanical behaviour may take place after the depercolation of the cementitious phase or at a certain overall volumetric content of elastic phases.

Figure 1

The volumetric changes in the system driven by breaking of emulsion and partial elimination of water, but also hydration of cement, directly influence the total volume fraction of the pore space and its dependence on time. This is the main factor that determines the overall behaviour of the material. Other factors are the ability of the emulsion to wet the solids, mainly responsible for the adhesion properties [36], and the final morphology of the bituminous film [37]. Depending on the composition of the co-binder system, commonly expressed by $b / c$, i.e. on the dominance of one or another co-binder, different scenarios of temporal change in volumetric structure, and consequentially macroscopic mechanical properties as an interplay between a viscous and an elastic material may exist [38].

The macroscopic mechanical properties of such heterogeneous media depend on the mechanical properties of the individual phases, as well as on their phase geometry [35], which is influenced by complex temporal interactions between the phases. Predicting the macromechanical behaviour of composites based on the mechanical properties of the individual phases and the microstructure has proven to be a challenging task [34]. For this reason, a proven experimental approach in the research of bitumen-emulsion cement composites is based on measuring the macromechanical properties of model systems at the length-scale of mortar $[1,16,39,40]$.

The overall aim of this research was to describe the mechanical behaviour of bitumen emulsion-cement composites, with special focus on the structural transition of the co-binder system. This goal was achieved by the following individual objectives: 
- A comprehensive characterisation of the mechanical behaviour of bitumen emulsioncement composites under cyclic indirect tensile loading in a range of temperatures and frequencies at different stages of curing;

- An analysis of impact of the structural transition of the co-binder from cementdominated to bitumen-dominated on the mechanical properties across a range of $b / c$ and with different emulsifier contents; and

- The identification of a critical $b / c$ corresponding to the structural transitions of these composites.

These objectives were addressed by examining (a) the mechanical behaviour by cyclic indirect tensile testing and (b) the structural morphology of bitumen emulsion-cement composites by X-ray microtomography of a model system of standardised bitumen emulsion mortar (BEM) with three different $b / c$ and two emulsifier contents.

\section{$2 \quad$ Materials and methods}

\subsection{Materials}

To investigate the effect of different emulsifier contents, two bitumen emulsions of type C60B1 (according to EN 13808) were produced with a quaternary ammonium salt cationic emulsifier in the amount of $1 \%$ (commonly applied amount in emulsions) and $1.5 \%$ (high amount of emulsifier) by mass of the emulsion. The base bitumen used for the emulsion was paving grade bitumen $70 / 100$ from naphthenic crude, which comprised $60 \%$ by mass of the emulsion (whose main properties are provided in Table 1). The $\mathrm{pH}$ value of the aqueous phase in both emulsions was adjusted to 2.5 with hydrochloric acid to activate the emulsifier and increase the stability of the emulsion.

\section{Table 1}

The cement used in this research was ordinary Portland cement CEM I $42.5 \mathrm{~N}$ (according to EN 197-1), with the mass content of clinker phases $\mathrm{C}_{3} \mathrm{~S}, \mathrm{C}_{2} \mathrm{~S}, \mathrm{C}_{3} \mathrm{~A}$, and $\mathrm{C}_{4} \mathrm{AF}$ of $65.1,14.9$, 8.6, and $6.1 \%$, respectively calculated form its oxide composition [41]. The Blaine fineness and the density were $2980 \mathrm{~cm}^{2} / \mathrm{g}$ and $3.120 \mathrm{~g} / \mathrm{cm}^{3}$, respectively. The potential heat of 
hydration was determined as $500 \mathrm{~J} / \mathrm{g}$ and was obtained by a linear combination of the mass fractions of the individual phases with their mass-normalised enthalpies (assumed to be 517, $262,1144$, and $468 \mathrm{~J} / \mathrm{g}$, respectively $[42,43])$. The chemically- and physically-bound water corresponding to full hydration [44] was calculated as 0.429 by mass of the cement.

The mixture used in this research was based on the bitumen emulsion mortar concept which was developed and studied in previous research $[1,16,39,40]$. The BEM is a model system developed with the purpose of focussing on the fundamental interaction mechanisms between bitumen emulsion and cement. The BEM mixture was composed of bitumen emulsion, cement, and standardised sand. The particle size distribution of the sand is provided in Table 2. The use of standardised fine aggregate is meant to exclude any variation in chemical, geometrical, and other properties of the aggregate. The exclusion of large aggregates in this model system allows mixing smaller quantities of materials and obtaining smaller representative volume elements, which is useful for various tests beyond this specific research.

Table 2

To investigate the effect of a range of $b / c$ and different emulsifier contents, mixtures were prepared with emulsions containing 1 and $1.5 \%$ of emulsifier and with the three $b / c$ of 1,2 , and 4 (i.e., six different mixtures). The content of sand by mass was $87.5 \%$ for all mixtures. The composition of the BEM mixtures and the mass ratios of the individual phases are shown in Table 3.

Table 3

\subsection{Specimen compaction and curing}

The mortar mixture was produced by mixing the sand particles with the bitumen emulsion first and adding the cement afterwards. The mixture was compacted immediately after mixing by a gyratory compactor (according to EN 12697-31) to obtain the cylindrical specimens of $100 \mathrm{~mm}$ in diameter and $60 \mathrm{~mm}$ in height with the target initial void content of $10 \%$. The specimens were compacted by applying the vertical pressure of $400 \mathrm{kPa}$, corresponding to the 
total vertical force of $3.14 \mathrm{kN}$ with the rate of 30 gyrations per minute. The vertical pressure was reduced from standard $600 \mathrm{kPa}$ to $400 \mathrm{kPa}$ to slightly extend the time of compaction, and thus stimulate the emulsion breaking and re-positioning of the aggregate [45, 46]. A group of four specimens was prepared for each of the six composites and all the results about these groups were reported. At the end of the compaction, the average bulk densities by dimensions of the specimens (according to EN 12697-6) with the $b / c$ of 1, 2, and 4 were 2.362, 2.297, and $2.253 \mathrm{~g} / \mathrm{cm}^{3}$, respectively. The actual initial average volumetric composition of the specimens calculated from the resulting void contents based on the height of the specimens is provided in Table 4.

Table 4

The resistance of the individual mixtures to compaction was evaluated by the total energy of compaction and the compactability, a parameter obtained by a logarithmic model based on the data on the vertical displacements (according to EN 12697-10), by the following equations:

$$
\begin{gathered}
E_{\mathrm{c}}(n)=\sigma_{\mathrm{c}} A \sum_{i=1}^{n} \Delta v_{i} \\
V(n)=V(1)-K \ln n
\end{gathered}
$$

where $E_{\mathrm{c}}$ is the compaction energy, $\sigma_{\mathrm{c}}$ is the average vertical compaction pressure, $A$ is the surface of the specimen base, $v_{i}$ is the vertical displacement corresponding to $i$-th gyration, $n$ is the number of gyrations, $V$ is the void content, and $K$ is the compactability. In Equation (2), $V(1)$ and $K$ were determined as regression parameters. As common practice for this type of analysis, the initial consolidation of the mixture at the beginning of the compaction was disregarded. The reason for this is that the initial consolidation is in fact significantly affected by other not material-related effects like the way the moulds were filled and cannot be attributed to the mixture composition. Therefore, the model fitting was based only on the gyrations with void content below $15 \%$.

A photograph of the specimens of the six composites seven days after compaction is shown in Figure 2. It can be seen that the specimens with the lowest $b / c$ had lighter surface and resembled cementitious materials, while the surface became darker with the increase in $b / c$. 
Furthermore, specimens with higher emulsifier content (S5) were slightly darker, which is a result of better coating of the aggregate by the emulsion containing more emulsifier.

Figure 2

After compaction, the specimens were cured at the relative humidity of (70 \pm 3$) \%$ and the temperature of $(20 \pm 0.5){ }^{\circ} \mathrm{C}$ and stored on a plain metal surface enabling free evaporation of water from all sides except form the bottom. Thanks to this approach, the curing conditions were precisely defined and reproducible in laboratory conditions. At the same time, it must be remarked that, due to different boundary conditions, the average water content and the distribution of the residual water can be different to those in an actual pavement layer. The specimens were cured for 84 days, even after the end of mechanical testing, with regular measurements of their mass. Based on the results, the residual to initial water content mass ratio, $w(t) / w_{\text {in }}$, was calculated as

$$
\frac{w(t)}{w_{\text {in }}}=1-\frac{m_{\text {spec,in }}-m_{\text {spec }}(t)}{w_{\text {in }} m_{\text {spec }, \text { in }}},
$$

and modelled by the following logarithmic regression model as a function of time on the domain with decrease in mass of specimens being apparent:

$$
\frac{w(t)}{w_{\text {in }}}=a_{1} \ln t+a_{0},
$$

where $w(t)$ is the mass fraction of water in the specimen at the time $t, w_{\text {in }}$ is the initial mass fraction of water, $m_{\mathrm{spec}, \text { in }}$ is the initial mass of the specimen, $m_{\mathrm{spec}}(t)$ is the mass of the specimen at the time $t$, and $a_{1}$ and $a_{0}$ are parameters of the regression model. The initial mass fraction of water in the specimen on the right-hand side of Equation (3) was calculated based on the above-defined composition and bulk densities and ranged from 3.01 to $4.24 \%$, depending on the group of specimens.

After curing and all mechanical tests were completed, three undisturbed cubic specimens with the approximate size of $1 \mathrm{~cm}^{3}$ were sawed from the middle intact part of the original cylindrical specimens with $1 \%$ of emulsifier, approximately $25 \mathrm{~mm}$ from the axes (see Figure 
3) by using a sintered segmented diamond blade. Neither water nor other lubricant was used to prevent any change in the content of the residual water.

\subsection{Mechanical testing}

The specimens were tested by applying cyclic indirect tension to determine their stiffness moduli at the temperatures of 5,10 , and $15^{\circ} \mathrm{C}$ and each at the frequencies of $0.1,0.5,1,5,10$, and $20 \mathrm{~Hz}$ (according to EN 12697-26) with the frequency of data acquisition of 128 readings per loading cycle. The specimens were tested after 3, 7, and 28 days of curing. This narrow temperature range was selected to prevent damage at both ends of the temperature range. On the one hand, to prevent freezing of the residual water in the specimens at temperatures below $0{ }^{\circ} \mathrm{C}$ and, on the other, to avoid an extensive permanent deformation of this low-stiffness material at temperatures above $15^{\circ} \mathrm{C}$.

The vertical cyclic load was applied over a $12.7 \mathrm{~mm}$-wide loading strip. The testing was performed in the stress-controlled mode in the linear viscoelastic range of the materials to minimise the permanent damage. Thus, the lower value of the horizontal normal stress in the centre of the specimens was fixed at $0.035 \mathrm{MPa}$, while its upper value was adjusted to obtain target values of the corresponding horizontal elastic strain in the centre of the specimen (commonly referred to as initial elastic strain). Preliminary testing showed that the specimens with the highest cement content were strong enough to resist higher loads, but because of their potential brittleness they were at risk of sudden fracture, especially at early stages of curing. On the other hand, specimens with the lowest cement content were quite ductile and were subjected to only low loading to avoid the development of high plastic deformations. Additionally, it is important to remark that all the specimens were foreseen to be tested multiple times over the entire curing period. For this reason, it was necessary to remain in the linear viscoelastic region and minimise the accumulation of damage.

For the above reasons, instead of applying an upper stress level corresponding to the initial elastic strain in the range from 0.05 to $0.10 \%$, as proposed by the specifications, each specimen was subjected to the upper stress sweep with ten cycles of loading per each stress level at all temperatures, frequencies, and curing stages. To avoid the influence of transient effect [47], first three and last two loading cycles were disregarded, and the analysis of the results was based on five intermediate loading cycles. As a result, upper stresses ranging 
from 0.05 to $0.30 \mathrm{MPa}$ corresponding to initial elastic strains ranging from $0.01 \%$, for higher stiffnesses (i.e. low $b / c$, lower temperatures, and higher frequencies), to $0.17 \%$, for lower stiffnesses, were adopted for further analysis. During the testing, vertical force, total lateral displacements, and total vertical displacements were measured. For the representative stress levels, these values were approximated by the following regression models:

$$
\begin{gathered}
F(t)=A+B \sin (2 \pi f t+C), \\
u(t)=a_{u}+b_{u} \sin \left(2 \pi f t+c_{u}\right)+d_{u} t, \\
v(t)=a_{v}+b_{v} \sin \left(2 \pi f t+c_{v}\right)+d_{v} t,
\end{gathered}
$$

where $F$ is the applied vertical force, $f$ is the loading frequency, $t$ is time, $u$ is the total lateral displacement, and $v$ is the total vertical displacement. The regression parameters $A, a_{u}$, and $a_{v}$ are shifts, $B, b_{u}$, and $b_{v}$ are amplitudes, $C, c_{u}$, and $c_{v}$ are phase angles, and $d_{u}$, and $d_{v}$ are linear drifts. After these regression parameters were determined, relevant parameters of the mechanical behaviour were based on the following relations:

$$
\begin{gathered}
\Delta \sigma_{x}=\frac{2 \Delta F}{\pi D H} \text { and } \Delta \varepsilon_{x} \equiv \varepsilon_{x, \mathrm{el}}=\frac{2 \Delta u}{D} \cdot \frac{1+3\left|v^{*}\right|}{4+\pi\left|v^{*}\right|-\pi}, \\
\left|E^{*}\right|=\frac{\Delta \sigma_{x}}{\Delta \varepsilon_{x}}\left(1+3\left|v^{*}\right|\right), \\
\varphi_{E^{*}}=\varphi_{u}-\varphi_{F}, \\
\varphi_{v^{*}}=\varphi_{v}-\varphi_{u}-\pi,
\end{gathered}
$$

where $\Delta F, \Delta \sigma_{x}, \Delta \varepsilon_{x}$, and $\Delta u$ are the ranges of the vertical force, horizontal normal stress, horizontal strain (referred to as the elastic strain, $\varepsilon_{x, \mathrm{el}}$ ), and total lateral displacement, respectively, $D$ and $H$ are the specimen diameter and height, respectively, $\left|\mathrm{E}^{*}\right|$ is the absolute value of the complex stiffness modulus (referred to as the stiffness modulus), $\left|v^{*}\right|$ is the absolute value of the complex Poisson's ratio (referred to as the Poisson's ratio), $\varphi_{E^{*}}$ is the phase angle corresponding to the stiffness modulus, and $\varphi_{v^{*}}$ is the phase angle corresponding to the Poisson's ratio. Knowing that by definition 


$$
\Delta F=2 B, \Delta u=2 b_{u}, \varphi_{F}=C, \varphi_{u}=c_{u}, \text { and } \varphi_{v}=c_{v},
$$

where $\varphi_{F}, \varphi_{u}$, and $\varphi_{v}$ are the phase angles of the vertical force, total lateral displacement, and total vertical displacement, the mechanical parameters were calculated as follows:

$$
\begin{gathered}
\left|E^{*}\right|=\frac{B}{b_{u} H}\left(\frac{4}{\pi}-1+\left|v^{*}\right|\right), \\
\varphi_{E^{*}}=c_{u}-C, \\
\varphi_{v^{*}}=c_{v}-c_{u}-\pi, \\
\varepsilon_{x, \mathrm{el}}=\frac{4 b_{u}}{D} \cdot \frac{1+3\left|v^{*}\right|}{4+\pi\left|v^{*}\right|-\pi} .
\end{gathered}
$$

The principle of the mechanical testing with the relevant stress and strain state in the centre of the specimen as well as the acquisition of experimental data are shown in Figure 3. The indicated strain $\varepsilon_{x}$ (Figure 3a) represents a horizontal strain the elastic part of which is the above-mentioned $\varepsilon_{x, \mathrm{el}}$.

Figure 3

Based on these data, the mechanical results were represented by master curves for the reference temperature of $10{ }^{\circ} \mathrm{C}$, Black diagrams, and Cole-Cole diagrams. The master curves were determined by the following model [48] by applying the time-temperature superposition principle using the Arrhenius equation:

$$
\begin{gathered}
\log a_{T}=-\frac{E_{\mathrm{a}}}{R}\left(\frac{1}{T}-\frac{1}{T_{r}}\right), \\
\left|E^{*}\right|=\left|E^{*}\right|_{-\infty}+\frac{\left|E^{*}\right|_{+\infty}-\left|E^{*}\right|_{-\infty}}{1+e^{z_{1} \log \left(\alpha_{T} f\right)+z_{0}}},
\end{gathered}
$$


where $a_{T}$ is the shift factor, $E_{\mathrm{a}}$ is the activation energy as a material-specific constant, $R=$ $8.314 \mathrm{~J} /(\mathrm{mol} \mathrm{K})$ is the universal gas constant (comprising $-E_{\mathrm{a}} / R$ as a single material-specific regression parameter), $T$ and $T_{r}$ are the test temperature and the reference temperature, respectively, $\left|E^{*}\right|_{-\infty}$ and $\left|E^{*}\right|_{+\infty}$ are the static and the glassy modulus, respectively and $z_{1}$ and $z_{0}$ are material-specific regression parameters. For the Cole-Cole diagrams, the storage modulus, $E_{1}$, as a measure of the elasticity, and the loss modulus, $E_{2}$, as a measure of the damping of the material were calculated by the following equations:

$$
E_{1}=\operatorname{Re} E^{*}=\left|E^{*}\right| \cos \varphi_{E^{*}} \text { and } E_{2}=\operatorname{Im} E^{*}=\left|E^{*}\right| \sin \varphi_{E^{*}} .
$$

Because of the complex stress and strain state in the indirect tensile test configuration, it is difficult to determine the Poisson's ratio based on the experimental data $[49,50,51]$. Therefore, the Poisson's ratio was determined by the following empirical equation [52] with the temperature as the only variable, although it is known that the Poisson's ratio is a complex function of both loading frequency and temperature [53]:

$$
\left|v^{*}\right|=0.15+\frac{0.35}{1+e^{1.83034-0.07619 T}}
$$

where $T$ is temperature in ${ }^{\circ} \mathrm{C}$. For the aforementioned reason, the results of the Poisson's ratio were used only for a comparative overview between the composites in the Cole-Cole diagram with respect to the corresponding phase angle, $\varphi_{v^{*}}$. It is to note that the above empirical equation was assumed to be relevant for bitumen emulsion-based materials, although the issue of its applicability depending on the type of material deserves more attention in future research. Analogously to Equation (19) and with the same interpretation, the real, $v_{1}$, and the imaginary part of the Poisson's ratio, $v_{2}$, were calculated by the following equations:

$$
v_{1}=\operatorname{Re} v^{*}=\left|v^{*}\right| \cos \varphi_{v^{*}} \text { and } v_{2}=\operatorname{Im} v^{*}=\left|v^{*}\right| \sin \varphi_{v^{*}} .
$$

\section{$2.4 \quad$ X-ray microtomography testing}

The X-ray microtomography testing was performed to explain the obtained mechanical response from the perspective of the structural morphology. Each of the small cubic 
specimens was tested using a setup (Easy Tomo XL by RX Solutions) with a micro-focus, direct transmission X-ray source and a flat panel X-ray detector. The X-ray source (Hamamatsu L10711-02) is equipped with a $\mathrm{LaB}_{6}$ filament and a $\mathrm{W}$ target on a $1 \mu \mathrm{m}$-thick diamond support, allowing achieving sub-micrometre X-ray source focal spot size. The X-ray detector (by Varian) consisted of a 2D array of amorphous Si pixels $(1920 \times 1536)$, each with the physical size of $p=127 \mu \mathrm{m}$, covered with a thin layer of CsI. The latter acted as a scintillator for the X-ray photons and converted them into visible light photons detected by the amorphous Si pixels.

The X-ray source was set to $95 \mathrm{kV}$ and $86 \mu \mathrm{A}$. For each specimen, the specimen-to-source distance, $d_{\mathrm{s}}$, was $62.69 \mathrm{~mm}$ while the source-to-detector distance, $d_{\mathrm{SD}}$, was $582.64 \mathrm{~mm}$. Given the small size of the X-ray source spot, the X-ray beam had cone geometry with a maximum angle of $140^{\circ}$ (dependent on X-ray source voltage and current). This beam geometry led to a geometrical magnification of the specimen projection on the detector plane depending on $d_{\mathrm{SS}}$ and $d_{\mathrm{SD}}$. The corresponding geometrical magnification factor, $M=d_{\mathrm{SD}} / d_{\mathrm{SS}}$, was approximately equal to 9.3 , leading to an effective pixel/voxel the size of $\tilde{p}=p / M=$ $13.66 \mu \mathrm{m}$ for the projected images (radiographs).

Each microtomography measurement consisted of 3600 acquired radiographs over $360^{\circ}$ of rotation angle for each specimen around the vertical axis. The final tomogram for each sample was obtained by 3D reconstruction of the set of radiographs using a GPU-optimized conebeam filtered back-projection algorithm [54] available in RX Solutions' software (XACT Ver. 1.1). The reconstructed data were saved as a stack of $2 \mathrm{D}$ cross-section digital slices coded as 16-bit unsigned integer TIFF images. The voxel values in the tomograms corresponded to the $\mathrm{X}$-ray attenuation coefficient $\mu$ of the composites, which is itself proportional to the atomic density, $N_{\mathrm{a}}$ (number of atoms per unit of volume) and to the atomic number, $Z$, at each voxel position in space. "Brighter" voxels indicated higher $\mu$ values and "darker" voxels indicated lower $\mu$ values. The effective spatial resolution of the final tomograms was approximately twice the effective voxel size, in this case about $28 \mu \mathrm{m}$ (estimated based upon calibration measurements). 
3.1 Compaction-related properties

The results of the compaction-related parameters of the mixtures are contained in Table 5 and diagrams of change in the void content and the total energy of compaction are shown in Figure 4. It can be observed that the total number of gyrations and the void content at one gyration decrease with $b / c$. The energy of compaction drastically decreased with the content of emulsion, and with $b / c$ of 4 , it dropped almost to half of the value with $b / c$ of 1 . The values of compactability of the mixtures with $b / c$ of 1 and 2 were around 3.27 and were very similar. However, the compactability of the mixtures with $b / c$ of 4 was significantly lower. From the compaction parameters and the shapes of the obtained compaction curves, it is apparent that the higher emulsifier content increased the compactability.

Table 5

Figure 4

\subsection{Loss of water}

The results of the ratio of residual to initial water content based on the mass measurements of the specimens, $w(t) / w_{\text {in }}$, are shown in Figure 5 with the regression parameters of the logarithmic model provided in Table 6. It can be observed that the specimens with higher emulsifier content lost more water, while the water loss increased with $b / c$. As usual for this type of material, the loss of water was most prominent in the first few days of curing [40, 55, $56,57,58]$. Even after 28 days of curing, the specimens contained a significant amount of water that is expected to have a direct effect on their mechanical properties. The decrease in the mass fraction of water in specimens with $b / c$ of 1 and 2 ended after approximately 7 and 42 days, respectively, and thereafter the water content remained almost constant. In contrast to that, specimens with $b / c$ of 4 were still losing water even after 84 days of curing. The logarithmic regression functions fitted remarkably well to the sequence of the measurement data with loss of water. The changes in dimensions of the specimens, provided in Table 7 , 
show a rough trend of increase in volumetric changes with $b / c$, which were, however, mostly within the measuring uncertainty.

\section{Figure 5}

Table 6

Table 7

\subsection{Mechanical properties}

The master curves of the specimens with 1 and $1.5 \%$ of emulsifier in the emulsion are shown in Figure 6, respectively. Because the measurements were done only in the temperature range from 5 to $15{ }^{\circ} \mathrm{C}$, the curves are presented only for the corresponding range of reduced frequencies. Two groups of curves with remarkably different values of stiffness modulus can be identified. On one hand, the specimens with $b / c$ of 1 had very high stiffness modulus in comparison to conventional hot asphalt mixtures, with the stiffness modulus considerably above $5000 \mathrm{MPa}$. On the other hand, the static modulus of the specimens with $b / c$ of 2 and 4 was drastically reduced, i.e. for more than $5000 \mathrm{MPa}$ on average. The obtained experimental data did not permit any reliable prediction of the glassy moduli of any of the specimens, due to the limited experimental temperature range. The curves for $b / c$ of 1 show a higher increase in stiffness between 3 and 7 days of curing, which slowed down between 7 and 28 days, while the specimens with $b / c$ of 2 and 4 showed the opposite trend. Except for the specimens with $b / c$ of 4 , the higher emulsifier content led to increases in the stiffness modulus.

Figure 6

Based on the calculated parameters of the time-temperature superposition of the specimens, the relationship between the shift factors and temperature was determined and characteristic examples at 7 days of curing are shown in Figure 7. As expected, it can be observed from Figure $7 \mathrm{a}$ that the temperature-dependence of the stiffness modulus of the material directly increased with $b / c$. Moreover, with the increase in the content of emulsifier, this dependence was less evident (especially at higher $b / c$ ), while at $b / c$ of 1 the emulsifier had practically no 
effect. At the same time, it is noticeable that the shift factors of the specimens are influenced by the time of curing, as shown in Figure 7b, regardless of the absolute values of the stiffness modulus itself. This phenomenon is more pronounced in the period from 7 to 28 days of curing. The applied elastic strains at which the measurements took place as a function of reduced frequency are shown in Figure 8. As explained in Section 2.3, the elastic strains increased with $b / c$, i.e. the deformability of the specimens decreased with the reduced frequency. The blue area represents the range of values specified for conventional asphalt mixtures (according to EN 12697-26).

Figure 7

Figure 8

Black diagrams and Cole-Cole diagrams of specimens with $1 \%$ emulsifier are shown in Figure 9 to Figure 11, while those of the specimens with $1.5 \%$ emulsifier are shown in Figure 12 to Figure 14. The phase angles of the specimens with $b / c$ of 1 are concentrated in a narrow range, roughly from 10 to $20^{\circ}$. They show no clear effect of temperature and have a minor reduction of values over time, indicating a distinct elastic behaviour that does not depend on time and temperature. The Cole-Cole diagram hardly represents the viscoelastic balance and has a large scatter of values, although there is a shift in favour of the storage modulus over time of curing. Contrary to this, the specimens with $b / c$ of 2 had a noticeable decrease in stiffness modulus with phase angle, and phase angles extending over a much wider range as the testing temperature increased, indicating a pronounced viscoelastic nature of these composites. In addition, as expected the phase angles gradually reduced over time of curing as the material became more elastic and less viscous. This trend continued for $b / c$ of 4 . As visible from the Cole-Cole diagrams, the increase in $b / c$ from 1 to 4 gradually led to changes in the viscoelastic balance of the material in favour of the loss modulus. The content of emulsifier had a slight influence on these values towards elastic behaviour. The dispersion of the values notably decreased with $b / c$ and time.

Figure 9

Figure 10

Figure 11 
Figure 12

Figure 13

Figure 14

The Cole-Cole diagrams of the Poisson's ratio are shown in Figure 15 and Figure 16. As explained in Section 2.3, the applied empirical equation resulted in three individual values of Poisson's ratio of $0.217,0.239$, and 0.261 at the three testing temperatures of 5,10 , and $15^{\circ} \mathrm{C}$, respectively. The results show an apparent increase in the imaginary part of Poisson's ratio with the increase in $b / c$ and the testing temperature, while the influence of curing was evident only at $b / c$ of 2 and 4 .

Figure 15

Figure 16

\subsection{X-ray microtomography}

The digital slices selected from X-ray tomograms for the specimens with $1 \%$ emulsifier are shown in Figure 17. The local increase in temperature caused by sawing affected the structure of the material only locally, within about $1 \mathrm{~mm}$ from the surface. The effect of sawing was manifested by a local densification clearly visible in the tomograms. However, the structure shown in Figure 17 corresponds to the middle part of the specimens and is far away from the affected zone. It can be observed that the structure of the composite gradually changed as $b / c$ increased. For the lowest $b / c$, the sand particles were densely packed. The residual bitumen almost everywhere appears to contain also material with higher X-ray attenuation (i.e. cement, hydration products, and filler), which makes it hard to distinguish the co-binder system from the surrounding sand particles. The presence of some unhydrated cement particles of characteristically high attenuation is noticeable. With the increase in $b / c$, the void content increased (corroborating the findings in Table 6) and the attenuation of the X-rays in the space between the sand particles decreased, confirming the lower content of the cement and unhydrated cement. At $b / c$ of 4 , the space between the mineral particles is filled with the cobinder system rich in bitumen, resembling the mesostructure [59] of conventional asphalt. Based on the presence of voids along the surface of the coarser particles [60], it can be 
inferred that the adhesion between the mastic, i.e. the mixture of the co-binder system and cement particles, and coarser sand particles became worse as $b / c$ decreased.

Figure 17

\section{Discussion}

Based on the results on the total residual content of water at the time of mechanical testing (Table 6), the residual $w / c$, the void content, and the volume contraction of the bituminous phase (decrease in volume of the bituminous phase by evaporating and binding of water in hydration products), $\theta_{\mathrm{BE}}$, was calculated and given in Table 8 . The volume contraction was calculated assuming full hydration of the cement, which is a rough but convenient approximation, because of insufficient knowledge about the long-term hydration kinetics of cement in these composites. For the same reason and to avoid dealing with unrealistic values at earlier ages, the volume contraction was calculated only for 28 days of curing. As it is obvious from the relations in Figure 5 and considering that the total chemically and physically bound $w / c$ of the used cement is 0.429 , it was impossible that the cement in the composites with $b / c$ of 1 could approach full hydration (depending also on the local distribution of water and its gradients in the specimens). The amount of water in composites with the other two values of $b / c$ was theoretically more than enough (although it is known that cement does not fully hydrate even in systems with high $w / c$ ).

As it can be observed from the values of the volume contraction, the bituminous phase experienced large volumetric changes during the curing period while transforming from bitumen emulsion to residual bitumen. The fact that no measurable volumetric changes could be detected on the surface of the specimens over time (Table 7), probably because of the high average volume fraction of sand of approximately $69 \%$ (Table 4) and the spatial organisation of its particles, means that the volume contraction and possibly depercolation of the bituminous phase took place in favour of the pore space [61]. For this reason, in improving the mechanical behaviour of these materials, one possible direction could be to limit the temporal internal volumetric changes, i.e. contraction of the co-binder system, and thus, keep the integrity of the adhesion between the co-binders and the aggregate during the percolation of the pore space. 
Table 8

The mixing method applied here is known in conventional asphalt technology as sequential mixing and allowed to obtain a homogeneous mixture and thicker coating around the coarser particles [62]. This mixing method minimised the risk of forming clusters of cement particles [63] that were hard to break and that might capture part of the emulsion by surface tension of liquid bridges between the cement particles $[64,65]$, thus making it unavailable for coating the aggregates. Moreover, in the case of emulsions susceptible to premature breaking, gradual addition of cement on the surface of the film of bitumen emulsion that is already partially adhered to the primary structure [62] prevents the agglomeration of bitumen droplets [17]. With this method of mixing, after the addition of cement on previously-coated sand particles, there was no chance of its segregation on the surface because it immediately stuck to the emulsion without the need for excessive mixing.

The results obtained by the total energy of compaction and the parameter of compactability can be explained as follows. First, as explained in Section 2.2, the initial consolidation of the mixtures was discarded by considering just the part with the void content below $15 \%$, which fitted well to the logarithmic model. In this phase of the compaction process, the applied energy was predominantly used for volumetric deformation without significant shear forces on the aggregate [66]. However, the standard approach in discarding the initial consolidation $[66,67]$ was not applicable to the mixtures with $b / c$ of 4 because their total number of gyrations was already very low, while the actual void contents at one gyration were around $14.5 \%$, slightly below the adopted threshold. This suggests that the used model was simply inapplicable, and the obtained parameters are irrelevant. This is also reflected on the slightly lower coefficients of determination given in Table 5.

Second, based on the experimental results it can be hypothesised that the sand particles in mixtures with high $b / c$ were covered with a soft porous structure of fine cement particles bridged by the bitumen emulsion, which caused the high void content at one gyration. Consequentially, the total number of gyrations and the total energy of compaction of these mixtures were relatively high. With an increase in the content of emulsion, this porous structure gradually changed to continuous bituminous film of lower viscosity and the energy of compaction to reach the target void content progressively decreased. This was confirmed 
by the total energy of compaction (Table 5), which is a measure of the workability and ability of the mixture to develop aggregate contacts and resist aggregate reorientation $[66,68,69]$. In fact, the total energy of compaction gradually reduced by half with the increase of $b / c$ from 1 to 4 .

From the master curves of stiffness modulus, which indicate the time-dependence of the material [70], it is clear that $b / c$ played a decisive role in defining the mechanical behaviour of the materials and the emulsifier content influenced it to a much lesser extent. Consequentially, the specimens with $b / c$ of 1 with their high stiffness performed closer similarly as cementbased materials, while the specimens with $b / c$ of 2 and 4 were comparable to other bituminous materials. This suggests that the stiffness at the lowest $b / c$ was dominated by the cement hydration products, while at higher $b / c$, the obtained stiffness was contributed by the residual bituminous binder, suggesting the existence of a percolation threshold.

The temperature-dependence of the material represented by the shift factor-temperature functions [70] (Figure 7) unambiguously showed a gradual trend to increase with $b / c$. This is contrary to the time-dependence obtained by the master curves that were grouped together for the specimens with $b / c$ of 2 and 4 . However, this confirms that the bituminous phase in the structure of the co-binder system percolates as the content of bitumen increased, leading to the temperature-dependence typical for bitumen-based. At the same time, the slight increase in the temperature-dependence of the material over the time of curing indicates the effect of emulsion breaking, as the bituminous film transforms from emulsion to residual bitumen.

The Black diagrams indicate that the testing temperature had almost no effect on the material with $b / c$ of 1 , while its effect became evident with an increase in the bitumen content, i.e. at $b / c$ of 2 and above. This indicates that the composites with high cement content were practically two-phase arrheodictic, i.e. solid-like, materials because the cementitious matrix remains elastic regardless of the temperature, while the bitumen droplets behave viscoelastically. With increase in $b / c$, the co-binder lost the internal elastic constraints and the rheological behaviour became defined by the viscoelastic properties of bitumen, and thus, time and temperature can be brought into superposition by a simple shift along the logarithmic frequency axis [71]. However, to be able to judge about the presence of the timetemperature superposition principle for the composites with high cement content, they should 
be additionally studied by rheological testing in a configuration that allows measuring across a much wider temperature and frequency range.

Based on the results of the mechanical properties, the critical composition of the co-binder system at which the transition from cement-dominated to bitumen-dominated mechanical behaviour took place at $b / c$ intermediate between 1 and 2, as illustrated in Figure 18, which is supported by the literature $[72,73,74,75,76]$. In this conceptual illustration, the percolation feature and the share of the bitumen-dominated behaviour are expressed in the range from 0 to 1 , where $b / c$ is used as the order parameter for the both processes. Considering the phase geometry of the co-binder system, this point was shifted to the right form the percolation threshold of bituminous phase and was in the domain of the suspension of discrete cementitious particles in the continuous bituminous binder as visible in Figure 17c. It is important to say that the critical concentrations leading to percolation of both phases, bituminous and cementitious, i.e. percolation thresholds, theoretically do not necessarily match (so called, mixed geometry [34]). Therefore, the observed shift can be explained by correspondence of the transition of the mechanical behaviour with a critical volumetric content of all elastic phases with aggregate playing the important role. Moreover, the percolation thresholds are decided by various material- and methodology-specific influences like viscosity and stability of the emulsion, interaction with cement during the preparation of specimens, agglomeration of cement particles, possible pre-mature demulsification, mixing procedure, etc. At the same time, the effect of the interference of the co-binder system by voids and filler particles on the respective length scale on the obtained properties is not to be neglected. Finally, it should be stressed that the percolation of pore space was an additional important factor for the temporal development of mechanical properties of the specimens.

Figure 18

\section{$5 \quad$ Conclusions}

This research comprehensively considered the cyclic indirect tensile-based mechanical behaviour of bitumen emulsion-cement composites in relation to the structural transition of the co-binder system taking place across a wide range of $b / c$ and emulsifier contents. 
At low $b / c$, the composite had a dominantly elastic behaviour, i.e. high stiffness modulus and low phase angles, with low temperature sensitivity of these properties, approaching the behaviour of cementitious materials. On the other hand, with the increase in $b / c$, the stiffness modulus was significantly reduced, and the phase angles increased, with pronounced temperature sensitivity of these properties. In other words, at higher $b / c$ the composite exhibited mechanical behaviour typical for bituminous materials. The content of emulsifier showed a less significant effect on the mechanical properties. Together with the insight into the morphology of these materials by X-ray computed microtomography, it can be concluded that the transition from cement-dominated to bitumen-dominated mechanical behaviour took place at $b / c$ between 1 and 2, corresponding to their volume ratio between 3 and 6 . The presence of the critical point for the mechanical behaviour can be caused by both the percolation of the cementitious phase, by the decrease in $b / c$, and percolation of the pore space and volume contraction of the co-binder system as $b / c$ increases. However, keeping the same void contents of all the composites across $b / c$ over time was impossible because of the different rates of volumetric change for different $b / c$.

The link between the critical morphological and mechanical features of these composites considered in his research provides a base for the optimisation of their volumetric composition and for the prediction of their fundamental mechanical behaviour. In further research, it is necessity to investigate the time-dependent spatial organisation of these composites in terms of the percolation of pore space, cementitious and bituminous binders, film thicknesses, but also properties like aggregate packing. For this purpose, it is critical to comprehensively, quantitatively describe phase geometries at different compositions based on X-ray microtomographic imaging. Furthermore, this would contribute to fundamental explanation of the transition of rheological properties of the co-binder system in relation to the percolation phenomena of the phase geometry. 


\section{Acknowledgement}

The authors thank Hilde Soenen (Nynas N.V., Belgium) for providing and testing the bitumen the emulsions were produced with, Tomas Svenson (AkzoNobel Surface Chemistry AB, Sweden) for producing the bitumen emulsions, and Peter Boos (Normensand GmbH and HeidelbergCement AG, Germany) for producing the modified standard sand and providing the cement. Michele Griffa (Empa, Swiss Federal Laboratories for Materials Science and Technology, Switzerland) is acknowledged for reconstructing the X-ray tomograms considered in this research. 


\section{References}

[1] Miljković, M. and Randenberg, M. 2014. Fracture behaviour of bitumen emulsion mortar mixtures. Construction and Building Materials, 62, 126-134. DOI: 10.1016/j.conbuildmat.2014.03.034

[2] Boucard, L., Schmitt, V., Farcasc, F., and Gaudefroy, V., 2015. Bitumen emulsions formulation and destabilisation process relationship: influence of salts addition. Road Materials and Pavement Design, 16 (S1), 330-348. DOI: 10.1080/14680629.2015.1030910

[3] Mercado, R. and Fuentes Pumarejo, L., 2016. Asphalt emulsions formulation: State-of-the-art and dependency of formulation on emulsions properties. Construction and Building Materials, 123, 162-173. DOI: 10.1016/j.conbuildmat.2016.06.129

[4] Lu, C.-T., Kuo, M.-F., and Shen, D.-H., 2009. Composition and reaction mechanism of cement-asphalt mastic. Construction and Building Materials, 23, 2580-2585. DOI: 10.1016/j.conbuildmat.2009.02.014

[5] Hu, S.-G., Wang, T., Wang, F.-Z., and Liu, Z.-C., 2009. Adsorption behaviour between cement and asphalt emulsion in cement-asphalt mortar. Advances in Cement Research, 21 (1), 11-14. DOI: 10.1680/adcr.2007.00034

[6] Ziyani, L., Gaudefroy, V., Ferber, V., Deneele, D., and Hammoum, F., 2014. Chemical reactivity of mineral aggregates in aqueous solution: relationship with bitumen emulsion breaking. Journal of Materials Science, 49 (6), 2465-2476. DOI: $10.1007 / \mathrm{s} 10853-013-7938-9$

[7] Ouyang, J., Hua, L., Li, H., and Han, B., 2018. Effect of cement on the demulsifying behavior of over-stabilized asphalt emulsion during mixing. Construction and Building Materials, 177, 252-260. DOI:

10.1016/j.conbuildmat.2018.05.141

[8] Bonakdar, L., Philip, J., Bardusco, P., Petkov, J., Potti, J.J., Méléard, P., and LealCalderon, F., 2001. Rupturing of bitumen-in-water emulsions: experimental evidence for viscous sintering phenomena. Colloids and Surfaces A: Physicochemical and Engineering Aspects, 176 (1-2), 185-194. DOI: 10.1016/S0927-7757(00)00699-3

[9] Derkach, S.R., 2009. Rheology of Emulsions. Advances in Colloid and Interface Science, 151, 1-23. DOI: 10.1016/j.cis.2009.07.001

[10] Tadros, T.F., 2010. Rheology of Dispersions: Principles and Applications. Weinheim: Wiley-VCH Verlag. DOI: 10.1002/9783527631568

[11] McClements, D.J., 2015. Food Emulsions: Principles, Practices, and Techniques, 3rd ed. Boca Raton, FL: Taylor \& Francis Group. DOI: 10.1201/b18868

[12] Khan, A., Redelius, P., and Kringos, N., 2016. Toward a new experimental method for measuring coalescence in bitumen emulsions: A study of two bitumen droplets. Colloids and Surfaces A: Physicochemical and Engineering Aspects, 494, 228-240. DOI: 10.1016/j.colsurfa.2016.01.045

[13] Boucard, L., Gaudefroy, V., Chailleux, E., Farcas, F., and Schmitt, V., 2017. Bitumen emulsion destabilization kinetics: importance of the crystallized wax content. Langmuir, 33 (38), 9740-9749. DOI: 10.1021/acs.langmuir.7b01578

[14] Garcia, A., Hassn, A., Chiarelli, A., and Dawson, A., 2015. Multivariable analysis of potential evaporation from moist asphalt mixture. Construction and Building Materials, 98, 80-88. DOI: 10.1016/j.conbuildmat.2015.08.061 
[15] Graziani, A., Godenzoni, C., Cardone, F., and Bocci, M., 2016. Effect of curing on the physical and mechanical properties of cold-recycled bituminous mixtures. Materials \& Design, 95, 358-369. DOI: 10.1016/j.matdes.2016.01.094

[16] Miljković, M., Radenberg, M., Fang, X., and Lura, P., 2017. Influence of emulsifier content on cement hydration and mechanical performance of bitumen emulsion mortar. Materials and Structures, 50 (3), 185. DOI: 10.1617/s11527017-1052-4

[17] Fang, X., Winnefeld, F., and Lura, P., 2016. Precipitation of anionic emulsifier with ordinary Portland cement. Journal of Colloid and Interface Science, 479, 98 105. DOI: 10.1016/j.jcis.2016.06.042

[18] Pang, J., Du, S., Chang, R., Pei, Q., and Cui, D., 2015. Effect of emulsifier content on the rheological properties of asphalt emulsion residues. Journal of Applied Polymer Science, 132 (15), 41806. DOI: 10.1002/APP.41806

[19] Tan, Y., Ouyang, J., and Li, Y., 2014. Factors influencing rheological properties of fresh cement asphalt emulsion paste. Construction and Building Materials, 68, 611-617. DOI: 10.1016/j.conbuildmat.2014.07.020

[20] Ouyang, J., Tan, Y., Li, Y., and Zhao, J., 2015. Demulsification process of asphalt emulsion in fresh cement-asphalt emulsion paste. Materials and Structures, 48, 12, 3875-3883. DOI: 10.1617/s11527-014-0446-9

[21] Ouyang, J., Han, B., Cao, Y., Zhou, W., Li, W., and Shah, S.P., 2016. The role and interaction of superplasticizer and emulsifier in fresh cement asphalt emulsion paste through rheology study. Construction and Building Materials, 125, 643-653. DOI: 10.1016/j.conbuildmat.2016.08.085

[22] Ouyang, J., Corr, D.J. and Shah, S.P., 2016. Factors Influencing the Rheology of Fresh Cement Asphalt Emulsion Paste. Journal of Materials in Civil Engineering, 28 (11), 04016140. DOI: 10.1061/(ASCE)MT.1943-5533.0001653

[23] Fang, X., Garcia, A., Winnefeld, F., Partl, M.N., Lura, P., 2016. Impact of rapidhardening cements on mechanical properties of cement bitumen emulsion asphalt. Materials and Structures, 49 (1-2), 487-498. DOI: 10.1617/s11527-014-0512-3

[24] Ouyang, J., Li, H., and Han, B., 2017. The rheological properties and mechanisms of cement asphalt emulsion paste with different charge types of emulsion. Construction and Building Materials, 147, 566-575. DOI: 10.1016/j.conbuildmat.2017.04.201

[25] Tan, Y., Ouyang, J., Lv, J., and Li, Y., 2013. Effect of emulsifier on cement hydration in cement asphalt mortar. Construction and Building Materials, 47, 159-164. DOI: 10.1016/j.conbuildmat.2013.04.044

[26] Li, W., Hong, J., Zhu, X., Yang, D., Bai, Y., Liu, J., Miao, C., 2018. Retardation mechanism of anionic asphalt emulsion on the hydration of Portland cement. Construction and Building Materials, 163, 714-723. DOI:

10.1016/j.conbuildmat.2017.12.150

[27] Pouliot, N., Marchand, J., and Pigeon, M., 2003. Hydration Mechanisms, Microstructure, and Mechanical Properties of Mortars Prepared with Mixed Binder Cement Slurry-Asphalt Emulsion. Journal of Materials in Civil Engineering, 15 (1), 54-59. DOI: 10.1061/(ASCE)0899-1561(2003)15:1(54)

[28] Li, W., Zhu, X., Hong, J., She, W., Wang, P., and Zuo, W., 2015. Effect of anionic emulsifier on cement hydration and its interaction mechanism. Construction and Building Materials, 93, 1003-1011. DOI: 10.1016/j.conbuildmat.2015.05.053

[29] Dolzycki, B., Jaczewski, M., and Szydlowski, C., 2017. The long-term properties of mineral-cement-emulsion mixtures. Construction and Building Materials, 156, 799-808. DOI: 10.1016/j.conbuildmat.2017.09.032 
[30] Faheem, A.F. and Bahia, H.U., 2010. Modelling of Asphalt Mastic in Terms of Filler-Bitumen Interaction. Road Materials and Pavement Design, 11 (S1), 281303. DOI: $10.1080 / 14680629.2010 .9690335$

[31] Lesueur, D., 2009. The colloidal structure of bitumen: Consequences on the rheology and on the mechanisms of bitumen modification. Advances in Colloid and Interface Science, 145 (1-2), 42-82. DOI: 10.1016/j.cis.2008.08.011

[32] Mignini, C., Cardone, F., and Graziani, A., 2018. Experimental study of bitumen emulsion-cement mortars: mechanical behaviour and relation to mixtures. Materials and Structures, 51 (6), 149. DOI: 10.1617/s11527-018-1276-y

[33] Torquato, S., 2002. Random Heterogeneous Materials - Microstructure and Macroscopic Properties. New York: Springer Science \& Business Media. DOI: 10.1007/978-1-4757-6355-3

[34] Nielsen, L.F., 2005. Composite Materials - Properties as Influenced by Phase Geometry. Berlin, Heidelberg: Springer-Verlag. DOI: 10.1007/978-3-540-27680-7

[35] Hashin, Z., 1970. Theory of Composite Materials. In: Wendt, F.W., Lebowitz, H., and Perrone, N. Ed. Mechanics of Composite Materials. Oxford: Pergamon Press, 201-242. DOI: 10.1016/B978-0-08-006421-5.50017-4

[36] Ziyani, L., Gaudefroy, V., Ferber, V., and Hammoum, F., 2016. A predictive and experimental method to assess bitumen emulsion wetting on mineral substrates. Colloids and Surfaces A: Physicochemical and Engineering Aspects, 489, 322335. DOI: 10.1016/j.colsurfa.2015.11.002

[37] Lesueur, D. and Potti, J.J, 2004. Cold mix design: A rational approach based on the current understanding of the breaking of bituminous emulsions. Road Materials and Pavement Design, 5 (1), 65-87. DOI: 10.1080/14680629.2004.9689988

[38] Ouyang, J., Zhao, J., and Tan, Y., 2018. Modeling Mechanical Properties of Cement Asphalt Emulsion Mortar with Different Asphalt to Cement Ratios and Temperatures. Journal of Materials in Civil Engineering, 30 (10), 04018263. DOI: 10.1061/(ASCE)MT.1943-5533.0002480

[39] Miljković, M. and Radenberg, M., 2015. Characterising the influence of bitumen emulsion on asphalt mixture performance. Materials and Structures, 48 (7), 21952210. DOI: $10.1617 / \mathrm{s} 11527-014-0302-y$

[40] Miljković, M. and Radenberg, M., 2016. Effect of compaction energy on physical and mechanical performance of bitumen emulsion mortar. Materials and Structures, 49 (1-2), 193-205. DOI: 10.1617/s11527-014-0488-z

[41] Taylor, H.F.W., 1989. Modification of the Bogue calculation. Advances in Cement Research, 2 (6), 73-77. DOI: 10.1680/adcr.1989.2.6.73

[42] Taylor, H.F.W., 1997. Cement chemistry. 2nd ed. London: Thomas Telford Publishing. DOI: 10.1680/cc.25929

[43] Bentz, D.P., 2008. A review of early-age properties of cement-based materials. Cement and Concrete Research, 38, 196-204. DOI:

10.1016/j.cemconres.2007.09.005

[44] Brouwers, H.J.H., 2004. The work of Powers and Brownyard revisited: Part 1. Cement and Concrete Research, 34, 1697-1716. DOI:

10.1016/j.cemconres.2004.05.031

[45] Swiertz, D., Johannes, P., Tashman, L., and Bahia, H., 2012. Evaluation of Laboratory Coating and Compaction Procedures for Cold Mix Asphalt. Journal of the Association of Asphalt Paving Technologies, 81, 81-107. 
[46] Grilli, A., Graziani, A., Bocci, E., and Bocci, M., 2016. Volumetric properties and influence of water content on the compactability of cold recycled mixtures.

Materials and Structures, 49 (10), 4349-4362. DOI: 10.1617/s11527-016-0792-x

[47] Gayte, P., Di Benedetto, H., Sauzéat, C., and Nguyen, Q.T., 2016. Influence of transient effects for analysis of complex modulus tests on bituminous mixtures. Road Materials and Pavement Design, 17 (2), 271-289. DOI:

10.1080/14680629.2015.1067246

[48] Pellinen, T.K., Witczak, M.W., and Bonaquist, R.F., 2002. Asphalt Mix Master Curve Construction Using Sigmoidal Fitting Function with Non-Linear Least Squares Optimization. Recent Advances in Materials Characterization and Modeling of Pavement Systems, Columbia University, New York. DOI: 10.1061/40709(257)6

[49] Kim, Y., Seo, Y., King, M., and Momen, M., 2004. Dynamic Modulus Testing of Asphalt Concrete in Indirect Tension Mode. Transportation Research Record, 1891, 163-173. DOI: 10.3141/1891-19

[50] Lee, H.S. and Kim, J., 2009. Determination of Viscoelastic Poisson's Ratio and Creep Compliance from the Indirect Tension Test. Journal of Materials in Civil Engineering, 21(8), 416-425. DOI: 10.1061/(ASCE)0899-1561(2009)21:8(416)

[51] Cao, W., Mohammad, L., and Barghabany, P., 2018. Use of indirect tension test and viscoelastic continuum damage theory for fatigue characterization of asphalt mixtures. Construction and Building Materials, 187, 38-49. DOI: 10.1016/j.conbuildmat.2018.07.191

[52] Witczak, M.W. and Mirza, M.W., 1999. Development of Relationships to Predict Poisson's Ratio for Paving Materials: Interteam Technical Report for NCHRP 137A. University of Maryland, College Park, MD.

[53] Graziani, A, Bocci, M., and Canestrari, F., 2014. Complex Poisson's ratio of bituminous mixtures: measurement and modelling. Materials and Structures, 47 (7), 1131-1148. DOI: 10.1617/s11527-013-0117-2

[54] Feldkamp, L.A., Davis, L.C., and Kress, J.W., 1984. Practical cone-beam algorithm. Journal of the Optical Society of America A, 1 (6), 612-619. DOI: 10.1364/JOSAA.1.000612

[55] García, A., Lura, P., Partl, M.N., and Jerjen, I., 2013. Influence of cement content and environmental humidity on asphalt emulsion and cement composites performance. Materials and Structures, 46 (8), 1275-1289. DOI: 10.1617/s11527012-9971-6

[56] Saadoon, T., Garcia, A., and Gómez-Meijide, B., 2017. Dynamics of water evaporation in cold asphalt mixtures. Materials \& Design, 134, 196-206. DOI: 10.1016/j.matdes.2017.08.040

[57] Dong, W., Xie, L., and Pan, P., 2018. A comparative study on early-stage strength development and mechanical properties of cement emulsified asphalt mixture using brake pad waste. Construction and Building Materials, 184, 515-523. DOI: 10.1016/j.conbuildmat.2018.07.013

[58] Saadoon, T., Gómez-Meijide, B., and Garcia, A., 2018. Prediction of water evaporation and stability of cold asphalt mixtures containing different types of cement. Construction and Building Materials, 186, 751-761. DOI: 10.1016/j.conbuildmat.2018.07.218

[59] Fu, J., Yang, Y., Zhang, X., and Wang, F., 2018. Different strain distributions of cement-emulsified asphalt concrete pavement between the macro- and mesoscale. Road Materials and Pavement Design, 19 (2), 470-483. DOI:

10.1080/14680629.2016.1259121 
[60] Tarefder, R.A. and Zaman, A.M., 2010. Nanoscale Evaluation of Moisture Damage in Polymer Modified Asphalts. Journal of Materials in Civil Engineering, 22 (7), 714-725. DOI: 10.1061/(ASCE)MT.1943-5533.0000072

[61] Ouyang, J., Pan, B., Xu, W., and Hu, L., 2019. Effect of Water Content on Volumetric and Mechanical Properties of Cement Bitumen Emulsion Mixture. Journal of Materials in Civil Engineering, 31 (6), 04019085. DOI: 10.1061/(ASCE)MT.1943-5533.0002736

[62] Hesami, E., Birgisson, B., and Kringos, N., 2015. Eff ect of mixing sequence on the workability and performance of asphalt mixtures. Road Materials and Pavement Design, 16 (S2), 197-213. DOI: 10.1080/14680629.2015.1077008

[63] Hesami, E., Bidewell, N., Birgisson, B., and Kringos, N., 2013. Evaluation of Environmental Susceptibility of Bituminous Mastic Viscosity as a Function of Mineral and Biomass Fillers. Transportation Research Record, No. 2371 (1), 2331. DOI: $10.3141 / 2371-03$

[64] Pietsch, W., 2002. Agglomeration Processes - Phenomena, Technologies, Equipment. Weinheim: Wiley-VCH Verlag. DOI: 10.1002/9783527619801

[65] Rhodes, M., 2008. Introduction to Particle Technology. 2nd ed. Chichester: John Wiley \& Sons. DOI: 10.1002/9780470727102

[66] Dessouky, S., Masad, E., and Bayom, F., 2003. Evaluation of Asphalt Mix Stability Using Compaction Properties and Aggregate Structure Analysis. International Journal of Pavement Engineering, 4 (2), 87-103. DOI: $10.1080 / 10298430310001597043$

[67] Goh, S.W. and You, Z., 2012. Mechanical Properties of Porous Asphalt Pavement Materials with Warm Mix Asphalt and RAP. Journal of Transportation Engineering, 138 (1), 90-97. DOI: 10.1061/(ASCE)TE.1943-5436.0000307

[68] Dessouky, S., Pothuganti, A., Walubita, L.F., and Rand, D., 2013. Laboratory Evaluation of the Workability and Compactability of Asphaltic Materials prior to Road Construction. Journal of Materials in Civil Engineering, 25 (6), 810-818.

[69] Ling, C. and Bahia, H.U., 2018. Development of a Volumetric Mix Design Protocol for Dense-Graded Cold Mix Asphalt. Journal of Transportation Engineering, Part B: Pavements, 144 (4), 04018039. DOI:

10.1061/JPEODX.0000071

[70] Anderson, D., Christensen, D., Roque, R., and Robyak, R., 1992. Rheological Properties of Polymer-Modified Emulsion Residue. In: Wardlaw, K. and Shuler, S., ed. Polymer Modified Asphalt Binders. West Conshohocken, PA: ASTM International, 20-34, DOI: 10.1520/STP17824S

[71] Fesko, D.G. and Tschoegl, N.W., 1971. Time- temperature superposition in thermorheologically complex materials. DOI: 10.1002/polc.5070350106

[72] Li, G., Zhao, Y., Pang, S.-S., and Huang, W., 1998. Experimental study of cementasphalt emulsion composite. Cement and Concrete Research, 28 (5), 635-641.

DOI: 10.1016/S0008-8846(98)00038-6

[73] Song, H., Do, J., and Soh, Y., 2006. Feasibility study of asphalt-modified mortars using asphalt emulsion. Construction and Building Materials 20, 332-337. DOI: 10.1016/j.conbuildmat.2005.01.027

[74] Bołtryk, M. and Małaszkiewicz, D., 2013. Application of anionic asphalt emulsion as an admixture for concrete. Construction and Building Materials 40, 556-565.

DOI: 10.1016/j.conbuildmat.2012.11.110 
[75] Yongliang, L., Xiangming, K., Yanrong, Z., and Peiyu, Y., 2013. Static and Dynamic Mechanical Properties of Cement-Asphalt Composites. Journal of Materials in Civil Engineering, 25 (10), 1489-1497. DOI:

10.1061/(ASCE)MT.1943-5533.0000681

[76] Wang, Z., Wang, Q., and Ai, T., 2014. Comparative study on effects of binders and curing ages on properties of cement emulsified asphalt mixture using gray correlation entropy analysis. Construction and Building Materials, 54, 615-622. DOI: 10.1016/j.conbuildmat.2013.12.093 


\section{List of figures:}

Figure 1 - Illustration of the percolation of a general two-dimensional two-phase system of overlapping disks: (a) concentration of Phase 1 below the percolation threshold and (b) concentration of Phase 1 above the percolation threshold.

Figure $2-$ Photograph of the specimens seven days after compaction. Upper row: $\mathrm{e}=1 \%$ (S1 to S3), lower row: e $=1.5 \%$ (S4 to S5), from left to right: $b / c$ of 1,2 , and 4 .

Figure 3 - Principle of the mechanical testing: (a) the test setup with indication of the considered mechanical quantities (vertical stress, horizontal, and vertical strain) in the centre of the specimens and (b) example of the experimental data on the relationship between these quantities during three seconds of testing of the specimen S2.4 at the load frequency of $1 \mathrm{~Hz}$, temperature of $5{ }^{\circ} \mathrm{C}$, and upper and lower values of the horizontal stress of 141 and $35 \mathrm{kPa}$, respectively.

Figure 4 - Relationships between the parameters of gyratory compaction from the number of gyrations: (a) void content and (b) total energy of compaction.

Figure 5 - Residual to initial water mass ratio over time (average with standard deviation) for the individual groups of specimens with the regression functions determined at the domain of the time of curing at which decrease in mass of specimens was apparent. The dashed lines represent the total physically and chemically bound water to initial water mass ratio at full hydration.

Figure 6 - Master curves of the composites for the reference temperature of $10{ }^{\circ} \mathrm{C}$ at different curing times: (a) specimens with $1 \%$ of emulsifier and $b / c$ of 1 (S1), 2 (S2), and 4 (S3), and (b) specimens with $1.5 \%$ of emulsifier and b/c of 1 (S4), 2 (S5), and 4 (S6).

Figure 7 - Model-based relationship between shift factor and temperature: (a) specimens with $1 \%$ of emulsifier and b/c of 1 (S1) and 4 (S3) at different stages of curing and (b) specimens with $1 \%$ of emulsifier and $b / c$ of 1 (S1), 2 (S2), and 4 (S3), and $1.5 \%$ of emulsifier and $b / c$ of 1 (S4), 2 (S5), and 4 (S6) after 7 days of curing.

Figure 8 - Relationship between the initial elastic strain and the reduced frequency applied during the testing of the specimens with $1 \%$ of emulsifier and different $b / c$ : (a) $b / c$ of 1 (S1), (b) $b / c$ of 2 (S2), and (c) b/c of 4 (S3), at different curing times.

Figure 9 - Black and Cole-Cole diagram of specimens with $1 \%$ of emulsifier and $b / c$ of 1 (S1) at different curing times: (a) Black diagram and (b) Cole-Cole diagram of stiffness modulus.

Figure 10 - Black and Cole-Cole diagram of specimens with $1 \%$ of emulsifier and $b / c$ of 2 (S2) at different curing times: (a) Black diagram and (b) Cole-Cole diagram of stiffness modulus.

Figure 11 - Black and Cole-Cole diagram of specimens with $1 \%$ of emulsifier and $b / c$ of 4 (S3) at different curing times: (a) Black diagram and (b) Cole-Cole diagram of stiffness modulus. 
Figure 12 - Black and Cole-Cole diagram of specimens with $1.5 \%$ of emulsifier and $b / c$ of 1 (S4) at different curing times: (a) Black diagram and (b) Cole-Cole diagram of stiffness modulus.

Figure 13 - Black and Cole-Cole diagram of the specimens with $1.5 \%$ of emulsifier and $b / c$ of 2 (S5) at different curing times: (a) Black diagram and (b) Cole-Cole diagram of stiffness modulus.

Figure 14 - Black and Cole-Cole diagram of the specimens with $1.5 \%$ of emulsifier and $b / c$ of 4 (S6) at different curing times: (a) Black diagram and (b) Cole-Cole diagram of stiffness modulus.

Figure 15 - Cole-Cole diagrams of the Poisson's ratio of specimens with $1 \%$ of emulsifier at different curing times: (a) $b / c$ of 1 (S1), (b) b/c of 2 (S2), and (c) b/c of 4 (S3).

Figure 16 - Cole-Cole diagrams of the Poisson's ratio of specimens with $1.5 \%$ of emulsifier at different during times: (a) $b / c$ of 1 (S4), (b) b/c of 2 (S5), and (c) b/c of 4 (S6).

Figure $17-\mathrm{X}$-ray tomograms of specimens with $1 \%$ of emulsifier: (a) $b / c$ of 1 , (b) $b / c$ of 2 , and (c) $b / c$ of 4 (RoI = region of interest).

Figure 18 - Illustration of the concept of the structural transition of the co-binder in relation to change in morphology and mechanical behaviour. 
Table 1 - Properties of the bitumen in the emulsions.

\begin{tabular}{|c|c|c|}
\hline Property & Standard & Value \\
\hline \multicolumn{3}{|l|}{ Original bitumen } \\
\hline Penetration at $25^{\circ} \mathrm{C}$ & EN 1426 & $84 \cdot 0.1 \mathrm{~mm}$ \\
\hline Softening point & EN 1427 & $46.2^{\circ} \mathrm{C}$ \\
\hline Flashpoint & EN ISO 2592 & $318^{\circ} \mathrm{C}$ \\
\hline Dynamic viscosity at $60^{\circ} \mathrm{C}$ & EN 12596 & $179 \mathrm{~Pa} \mathrm{~s}$ \\
\hline Kinematic viscosity at $135^{\circ} \mathrm{C}$ & EN 12595 & $369 \mathrm{~mm}^{2} / \mathrm{s}$ \\
\hline Fraass breaking point & EN 12593 & $-17^{\circ} \mathrm{C}$ \\
\hline Stiffness at $-16^{\circ} \mathrm{C}$ by bending beam rheometer & \multirow{4}{*}{ EN 14771} & $227 \mathrm{MPa}$ \\
\hline$m$-value by bending beam rheometer & & 0.467 \\
\hline Temperature corresponding to the stiffness of $300 \mathrm{MPa}$ & & $-18^{\circ} \mathrm{C}$ \\
\hline Temperature corresponding to the $m$-value of 0.300 & & $-22^{\circ} \mathrm{C}$ \\
\hline \multicolumn{3}{|l|}{ RTFOT-aged bitumen (EN 12607-1) } \\
\hline Change in mass & EN 12607-1 & -0.03 \\
\hline Increase in softening point & EN 1427 & $4.4^{\circ} \mathrm{C}$ \\
\hline Retained penetration & EN 1426 & $64.3 \%$ \\
\hline Dynamic viscosity ratio at $60^{\circ} \mathrm{C}$ & EN 12596 & 4.4 \\
\hline
\end{tabular}


Table 2 - Particle size distribution of the sand used for the BEM mixtures.

\begin{tabular}{|c|c|}
\hline Sieve size $(\mathrm{mm})$ & Percentage passing by mass (\%) \\
\hline 0.063 & 5 \\
\hline 0.125 & 9 \\
\hline 0.5 & 33 \\
\hline 1 & 67 \\
\hline 1.6 & 93 \\
\hline 2 & 100 \\
\hline
\end{tabular}


Table 3 - Parameters of the compositions of the BEM mixtures at the initial stage of curing.

\begin{tabular}{|l|c|c|c|}
\hline \multirow{2}{*}{\multicolumn{1}{|c|}{ Parameter }} & \multicolumn{3}{c|}{ Value } \\
\cline { 2 - 4 } & $b / c=1$ & $b / c=2$ & $b / c=4$ \\
\hline Mass content of bitumen emulsion (\%) & 7.81 & 9.62 & 10.87 \\
\hline Mass content of cement (\%) & 4.69 & 2.88 & 1.63 \\
\hline Mass content of sand (\%) & 87.5 & 87.5 & 87.5 \\
\hline $1 \%$ of emulsifier in emulsion & $\mathrm{S} 1$ & $\mathrm{~S} 2$ & $\mathrm{~S} 3$ \\
\hline Designation & 0.65 & 1.30 & 2.60 \\
\hline$w / c$ & 0.33 & 0.16 & 0.08 \\
\hline$\phi_{\mathrm{c}} / \phi_{\mathrm{b}}$ & \multicolumn{2}{|c|}{} \\
\hline $1.5 \%$ of emulsifier in emulsion & $\mathrm{S} 4$ & $\mathrm{~S} 5$ & $\mathrm{~S} 6$ \\
\hline Designation & 0.64 & 1.28 & 2.57 \\
\hline$w / c$ & 0.33 & 0.16 & 0.08 \\
\hline$\phi_{\mathrm{c}} / \phi_{\mathrm{b}}$ & \multicolumn{2}{|c|}{} \\
\hline
\end{tabular}

$\phi_{\mathrm{c}} / \phi_{\mathrm{b}}-$ volumetric ratio of cement to bitumen 
Table 4 - Initial average volumetric composition of the specimens based on the actual void content.

\begin{tabular}{|c|c|c|c|}
\hline \multirow{2}{*}{ Constituent } & \multicolumn{3}{|c|}{ Content by volume (\%) } \\
\hline & $b / c=1$ & $b / c=2$ & $b / c=4$ \\
\hline \multicolumn{4}{|c|}{$1 \%$ of emulsifier in emulsion } \\
\hline Bitumen & 9.7 & 11.7 & 13.0 \\
\hline Emulsifier & 0.2 & 0.2 & 0.2 \\
\hline Water & 6.5 & 7.8 & 8.7 \\
\hline Cement & 3.2 & 1.9 & 1.1 \\
\hline Sand & 70.6 & 68.9 & 68.0 \\
\hline Voids & 9.7 & 9.4 & 9.0 \\
\hline \multicolumn{4}{|c|}{$1.5 \%$ of emulsifier in emulsion } \\
\hline Bitumen & 9.7 & 11.7 & 12.9 \\
\hline Emulsifier & 0.2 & 0.3 & 0.3 \\
\hline Water & 6.4 & 7.7 & 8.5 \\
\hline Cement & 3.2 & 1.9 & 1.1 \\
\hline Sand & 70.7 & 69.1 & 67.4 \\
\hline Voids & 9.7 & 9.3 & 9.7 \\
\hline
\end{tabular}


Table 5 - Overview of the parameters from the gyratory compaction of the specimens.

\begin{tabular}{|c|c|c|c|c|c|c|}
\hline \multirow{3}{*}{ Parameter } & \multicolumn{6}{|c|}{ Value } \\
\hline & \multicolumn{2}{|c|}{$b / c=1$} & \multicolumn{2}{|c|}{$b / c=2$} & \multicolumn{2}{|c|}{$b / c=4$} \\
\hline & Average & $\begin{array}{l}\text { Standard } \\
\text { deviation }\end{array}$ & Average & $\begin{array}{l}\text { Standard } \\
\text { deviation }\end{array}$ & Average & $\begin{array}{l}\text { Standard } \\
\text { deviation }\end{array}$ \\
\hline \multicolumn{7}{|l|}{$1 \%$ of emulsifier in emulsion } \\
\hline Total number of gyrations, $n_{\text {total }}$ & 34.3 & 1.53 & 15.8 & 2.06 & 9.3 & 2.63 \\
\hline Initial void content, $V_{\text {in }} / \%^{(1)}$ & 9.7 & 0.09 & 9.4 & 0.08 & 9.0 & 0.29 \\
\hline Total energy of compaction, $E_{\mathrm{c}} / \mathrm{J}$ & 27.5 & 0.48 & 20.7 & 1.01 & 15.9 & 1.63 \\
\hline Void content at one gyration, $V(1) / \%^{(2)}$ & 21.2 & 0.29 & 18.7 & 0.76 & 15.3 & 1.74 \\
\hline Compactability, $K^{(2)}$ & 3.24 & 0.06 & 3.28 & 0.14 & 2.61 & 0.41 \\
\hline$R^{2}$ of the logarithmic model & 0.999 & 0.000 & 0.993 & 0.003 & 0.966 & 0.018 \\
\hline \multicolumn{7}{|l|}{$1.5 \%$ of emulsifier in emulsion } \\
\hline Total number of gyrations, $n_{\text {total }}$ & 29.8 & 7.32 & 12.5 & 1.91 & 7.0 & 0.82 \\
\hline Total energy of compaction, $E_{\mathrm{c}} / \mathrm{J}$ & 28.2 & 1.86 & 20.7 & 0.74 & 14.9 & 1.22 \\
\hline Initial void content, $V_{\text {initial }} / \%$ & 9.7 & 0.08 & 9.3 & 0.15 & 9.7 & 0.21 \\
\hline Void content at one gyration, $V(1) / \%^{(2)}$ & 21.0 & 0.88 & 17.6 & 0.95 & 14.9 & 0.86 \\
\hline Compactability, $K^{(2)}$ & 3.33 & 0.05 & 3.23 & 0.15 & 2.48 & 0.31 \\
\hline$R^{2}$ of the logarithmic model & 0.999 & 0.000 & 0.994 & 0.001 & 0.973 & 0.010 \\
\hline
\end{tabular}

(1) Void content achieved at the end of the compaction, corresponding to the initial stage of curing.

(2) Values predicted by regression. 
Table 6 - Overview of the regression parameters of the logarithmic model applied to a domain of the time of curing.

\begin{tabular}{|l|c|c|c|c|c|c|}
\hline \multirow{2}{*}{$\begin{array}{c}\text { Regression } \\
\text { parameter }\end{array}$} & \multicolumn{6}{|c|}{ Value } \\
\cline { 2 - 7 } & S1 & S2 & S3 & S4 & S5 & S6 \\
\hline Domain of $t$ /day & $1-7$ & $1-42$ & $1-84$ & $1-7$ & $1-42$ & $1-84$ \\
\hline$a_{1}$ & -11.2 & -8.45 & -10.0 & -10.8 & -7.57 & -13.0 \\
\hline$a_{0}$ & 81.1 & 81.1 & 73.3 & 74.7 & 73.1 & 74.6 \\
\hline$R^{2}$ & 0.990 & 0.993 & 0.992 & 0.977 & 0.993 & 0.988 \\
\hline
\end{tabular}


Table 7 - Change in dimensions of the specimens within the curing period of 28 days.

\begin{tabular}{|l|c|c|c|c|c|c|}
\hline \multirow{2}{*}{ Dimension } & \multicolumn{6}{c|}{ Change from 1 to 28 days of curing (\%o) } \\
\cline { 2 - 7 } & \multicolumn{2}{|c|}{$b / c=1$} & \multicolumn{2}{c|}{$b / c=2$} & \multicolumn{2}{c|}{$b / c=4$} \\
\cline { 2 - 7 } & Average & $\begin{array}{c}\text { Standard } \\
\text { deviation }\end{array}$ & Average & $\begin{array}{c}\text { Standard } \\
\text { deviation }\end{array}$ & Average & $\begin{array}{c}\text { Standard } \\
\text { deviation }\end{array}$ \\
\hline 1\% of emulsifier in emulsion \\
\hline Height & -0.21 & 1.7 & +4.9 & 4.5 & +3.8 & 3.6 \\
\hline Diameter & -0.5 & 0.4 & -2.3 & 3.1 & -15.4 & 8.1 \\
\hline $1.5 \%$ of emulsifier in emulsion \\
\hline Height & +2.1 & 0.0 & -8.0 & 26.0 & +9.6 & 11.3 \\
\hline Diameter & -2.4 & 0.4 & -2.8 & 2.8 & -7.8 & 2.9 \\
\hline
\end{tabular}


Table 8 - Average residual $w(t) / c$, void content, and volume contraction of the bituminous phase at the time of mechanical testing, assuming a degree of hydration of $\alpha=1$.

\begin{tabular}{|l|c|c|c|c|c|c|c|c|c|}
\hline Time of & \multicolumn{3}{|c|}{$w(t) / c$} & \multicolumn{3}{c|}{$V(\%)$} & \multicolumn{3}{c|}{$\theta_{\mathrm{BE}}$} \\
\cline { 2 - 11 } \\
curing, $t$ & $b / c=1$ & $b / c=2$ & $b / c=4$ & $b / c=1$ & $b / c=2$ & $b / c=4$ & $b / c=1$ & $b / c=2$ & $b / c=4$ \\
\hline $1 \%$ of emulsifier in emulsion \\
\hline 3 days & 0.450 & 0.935 & 1.59 & 12.8 & 12.7 & 13.6 & - & - & - \\
\hline 7 days & 0.391 & 0.828 & 1.35 & 13.4 & 13.3 & 14.4 & - & - & - \\
\hline 28 days & 0.365 & 0.682 & 1.04 & 13.6 & 14.2 & 15.4 & 0.434 & 0.318 & 0.302 \\
\hline $1.5 \%$ of emulsifier in emulsion \\
\hline 3 days & 0.404 & 0.840 & 1.54 & 13.2 & 13.1 & 13.7 & - & - & - \\
\hline 7 days & 0.349 & 0.738 & 1.20 & 13.7 & 13.7 & 14.8 & - & - & - \\
\hline 28 days & 0.322 & 0.606 & 0.836 & 14.0 & 14.5 & 16.0 & 0.456 & 0.337 & 0.329 \\
\hline
\end{tabular}


(a)

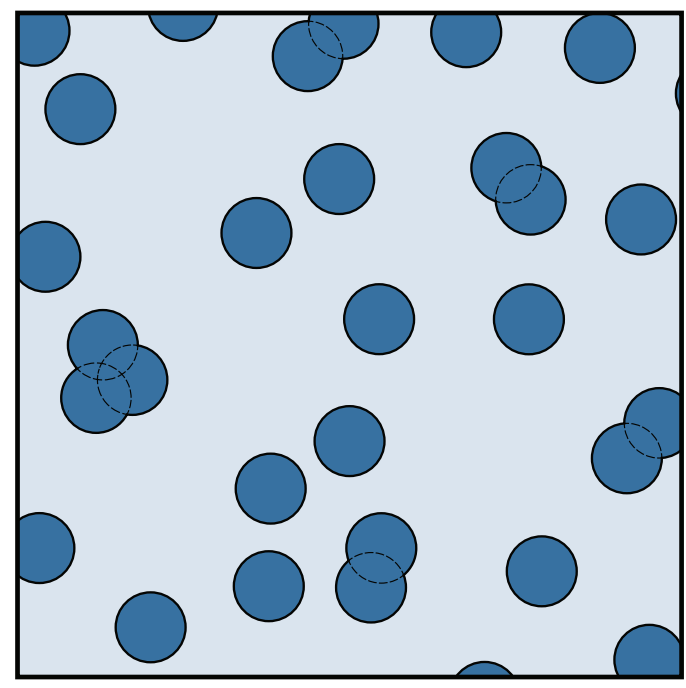

(b)

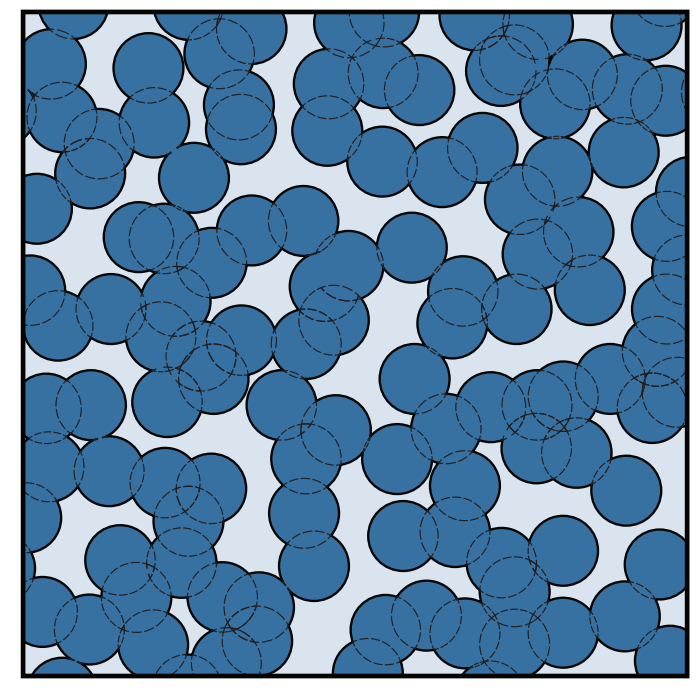

Phase 2

( 0 


\section{Figure 2}

Click here to download Figure: Figure 2.eps

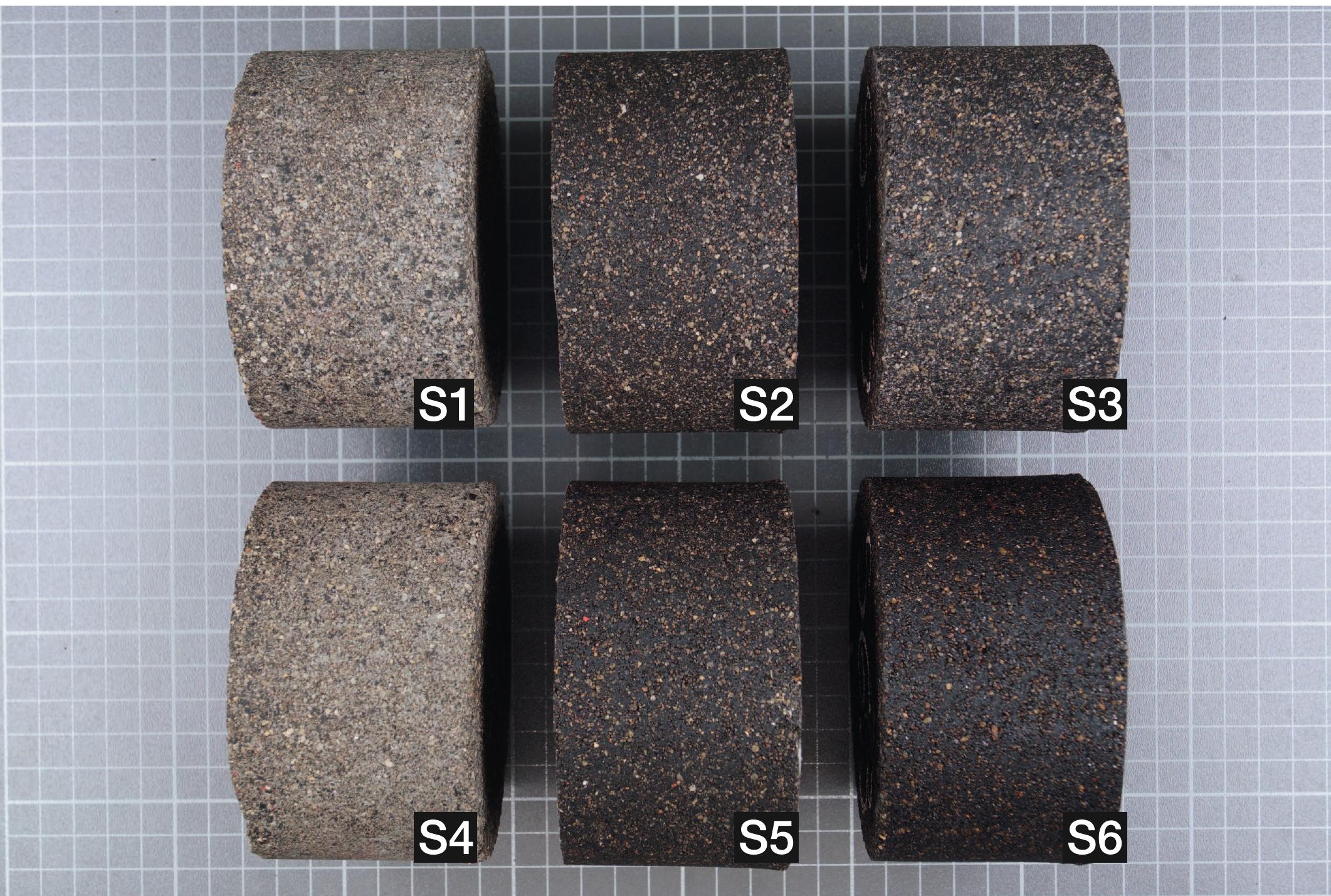


(a)

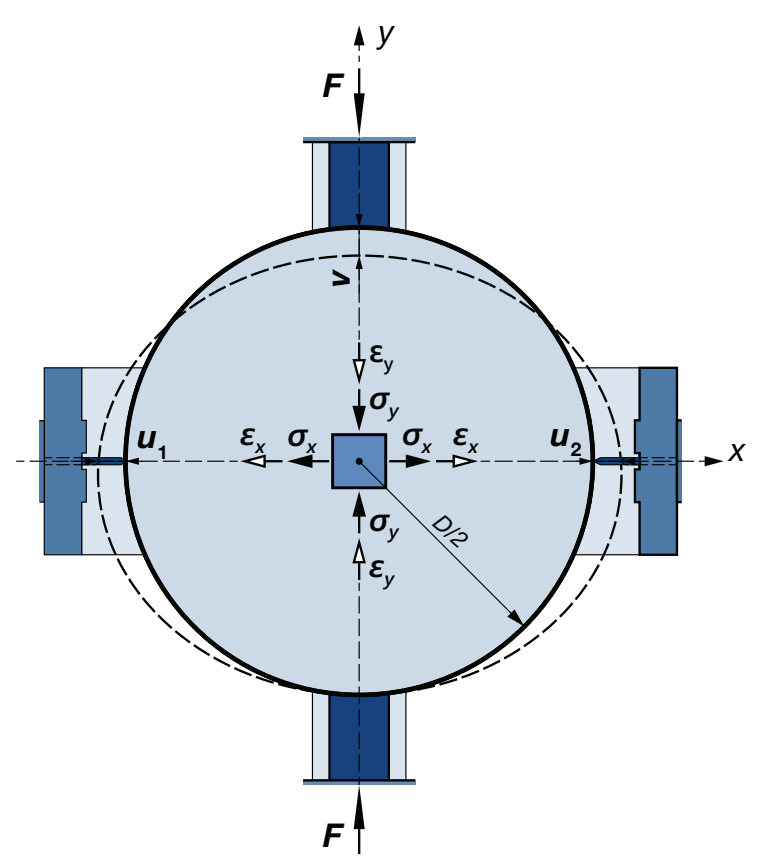

(b)

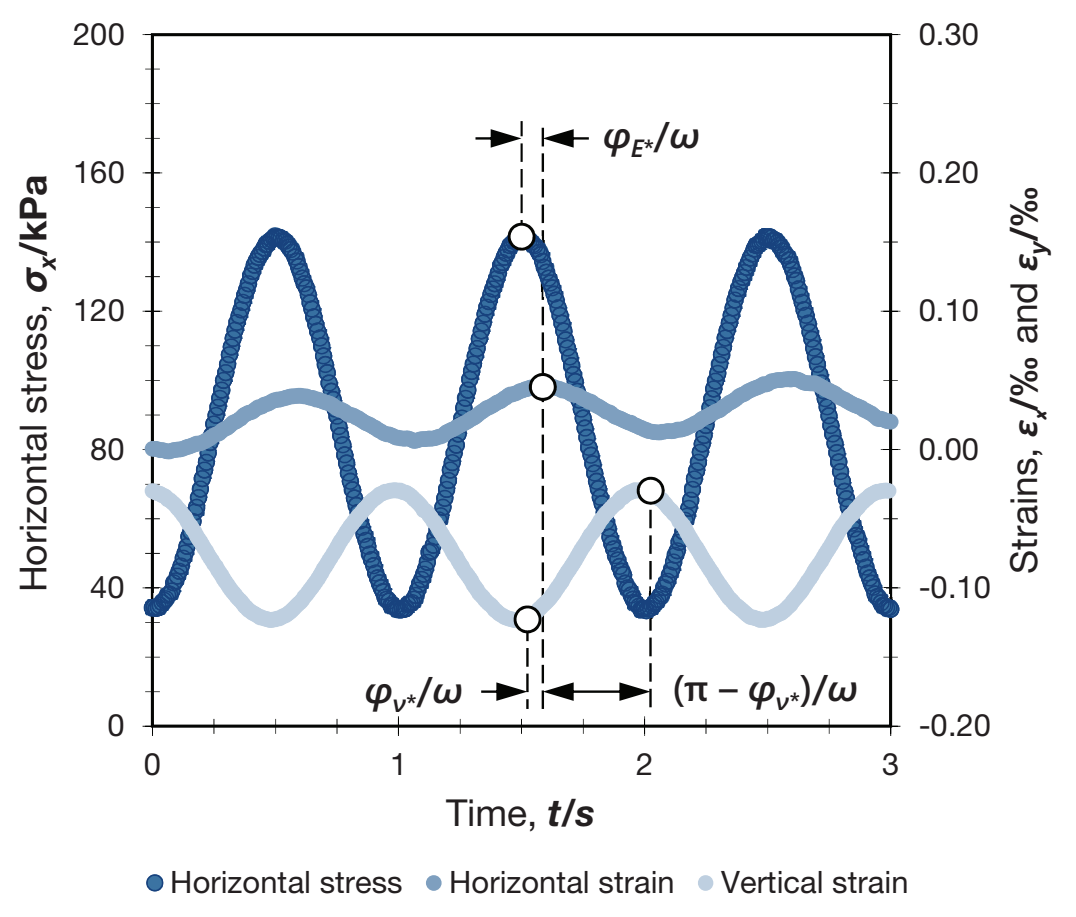




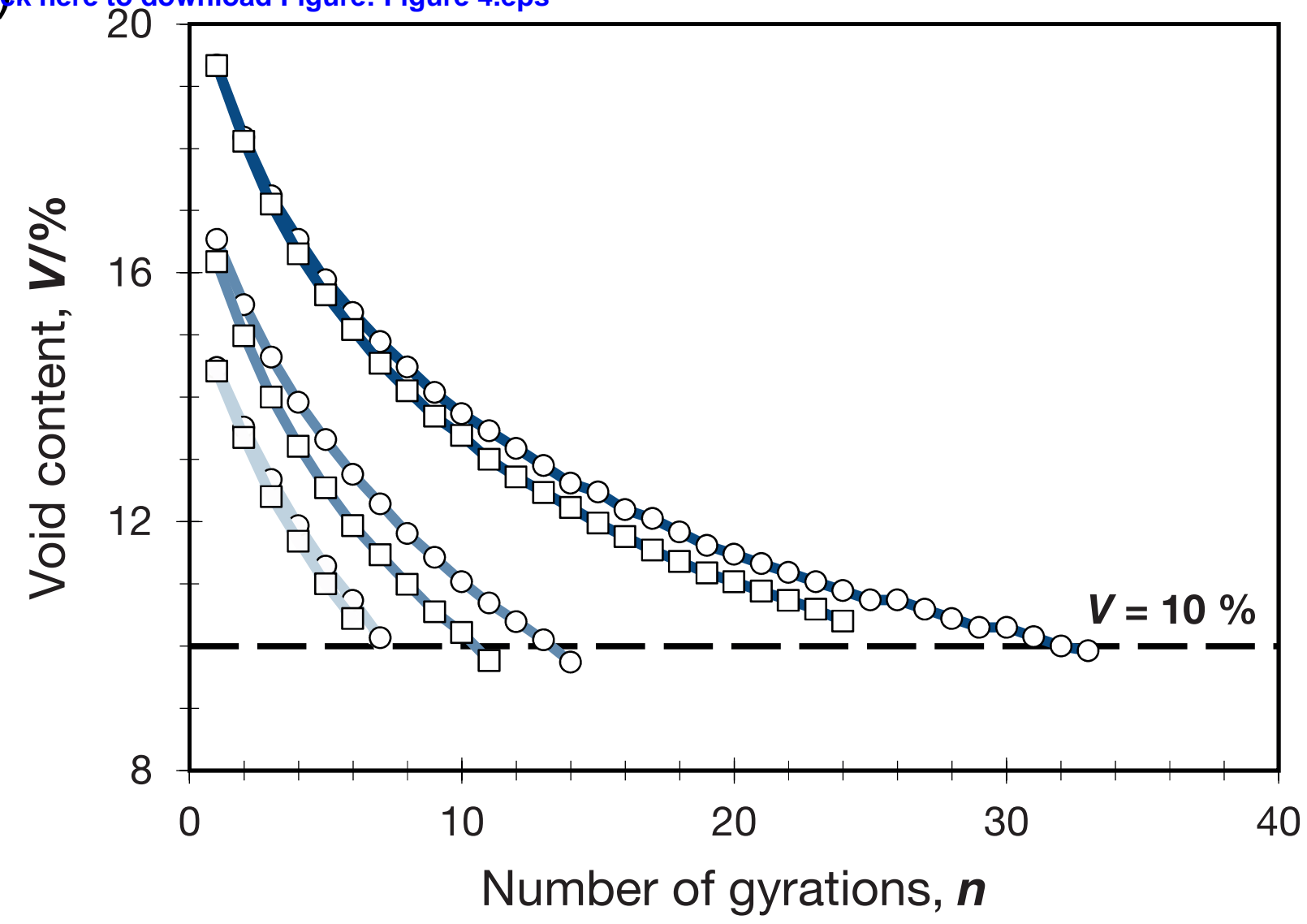

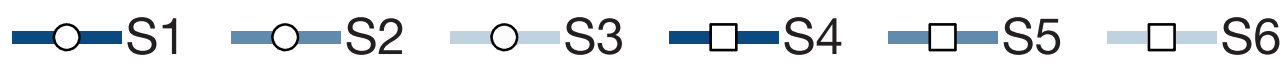

(b)

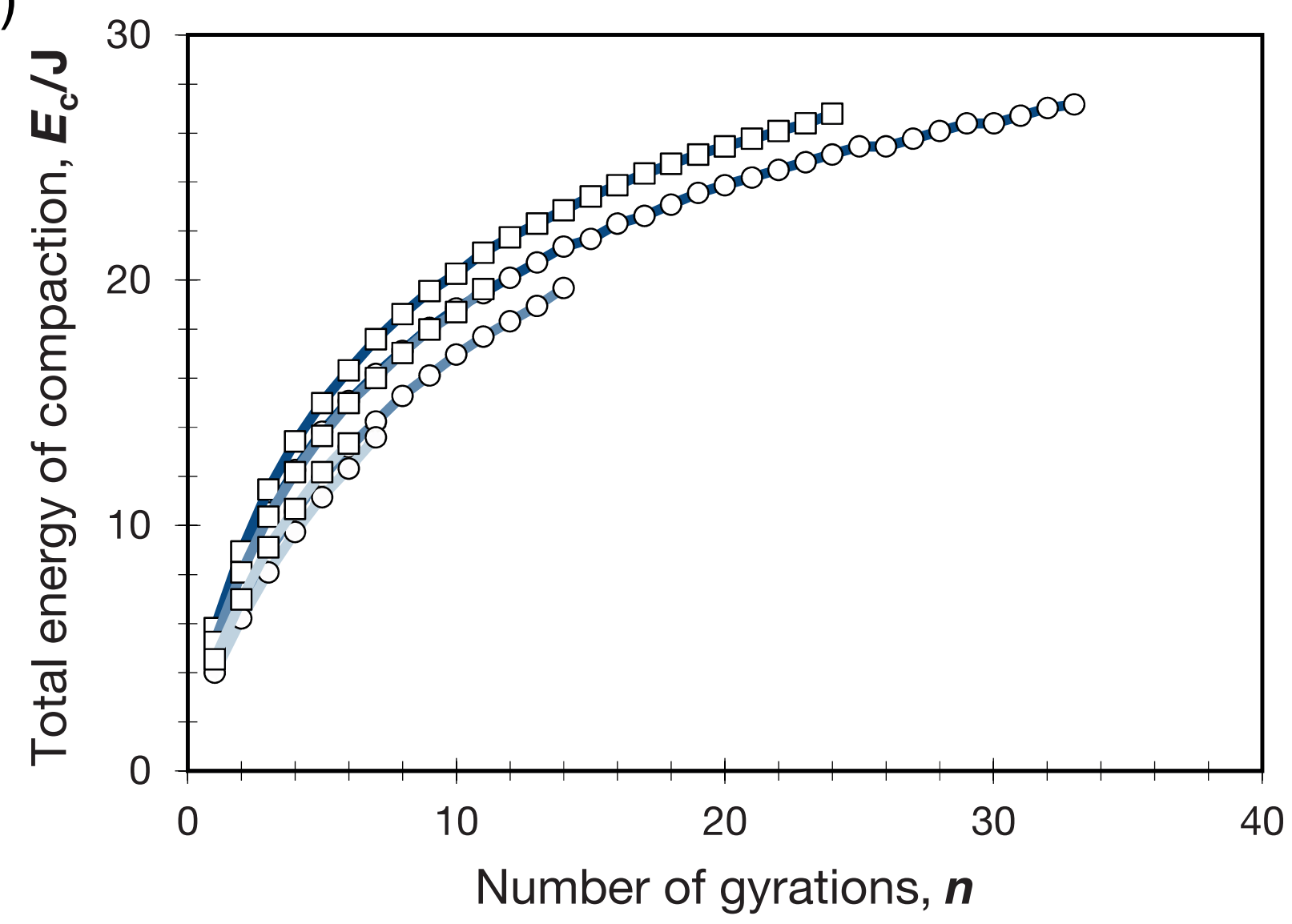

$\begin{array}{lllllllllll}-\mathrm{O}=\mathrm{S} 1 & \mathrm{O} & \mathrm{S} 2 & \mathrm{O} & \mathrm{S} 3 & \square & -\mathrm{S} 4 & \square & -\mathrm{S} 5 & \square & \mathrm{S} 6\end{array}$ 


\section{Figure 5}

Click here to download Figure: Figure 5.eps

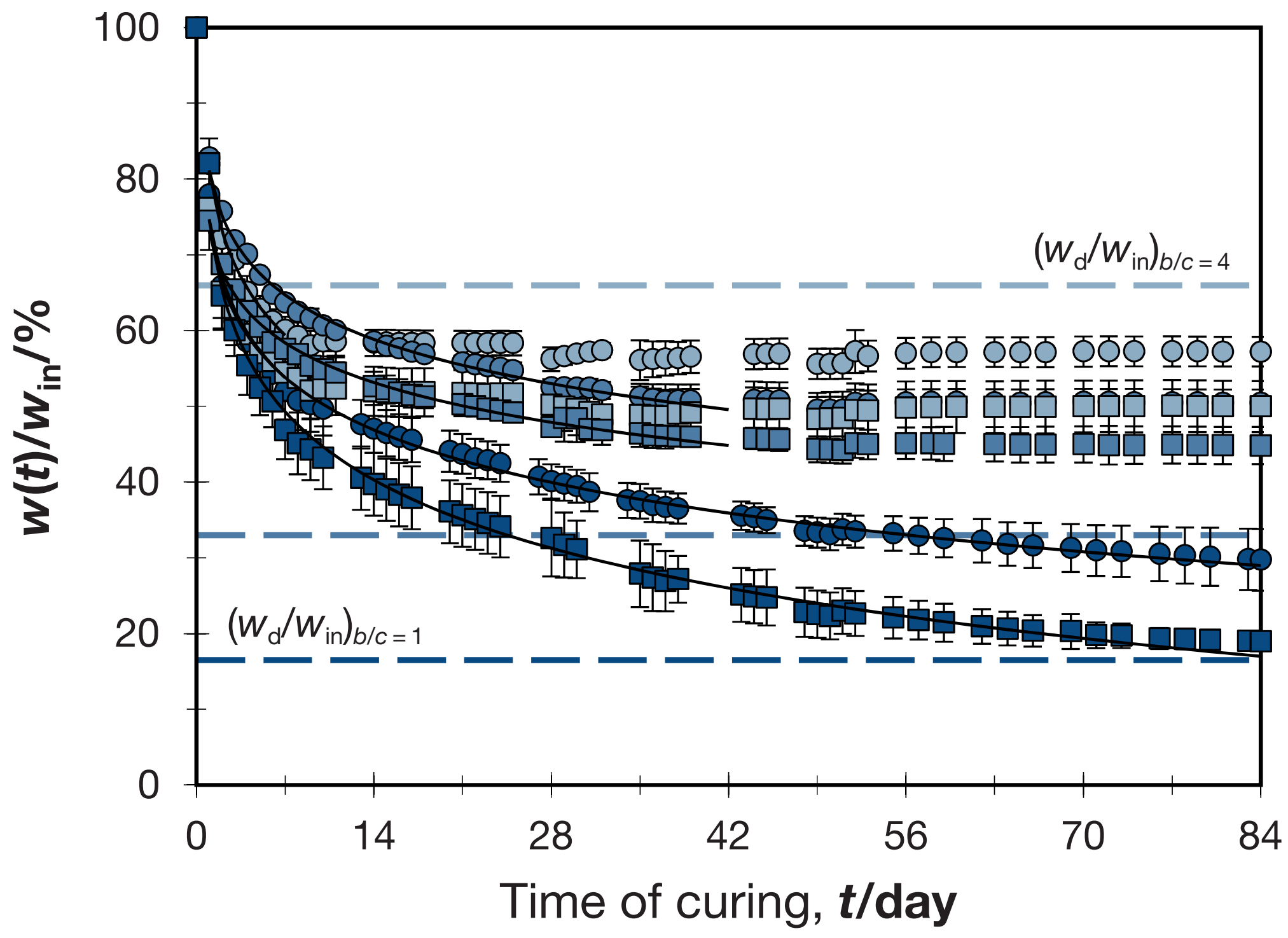

$\begin{array}{llllll}\text { oS1 } & \text { oS2 } & \text { oS3 } & \text { uS4 } & \text { uS5 } & \square S 6\end{array}$ 
(Kipurue
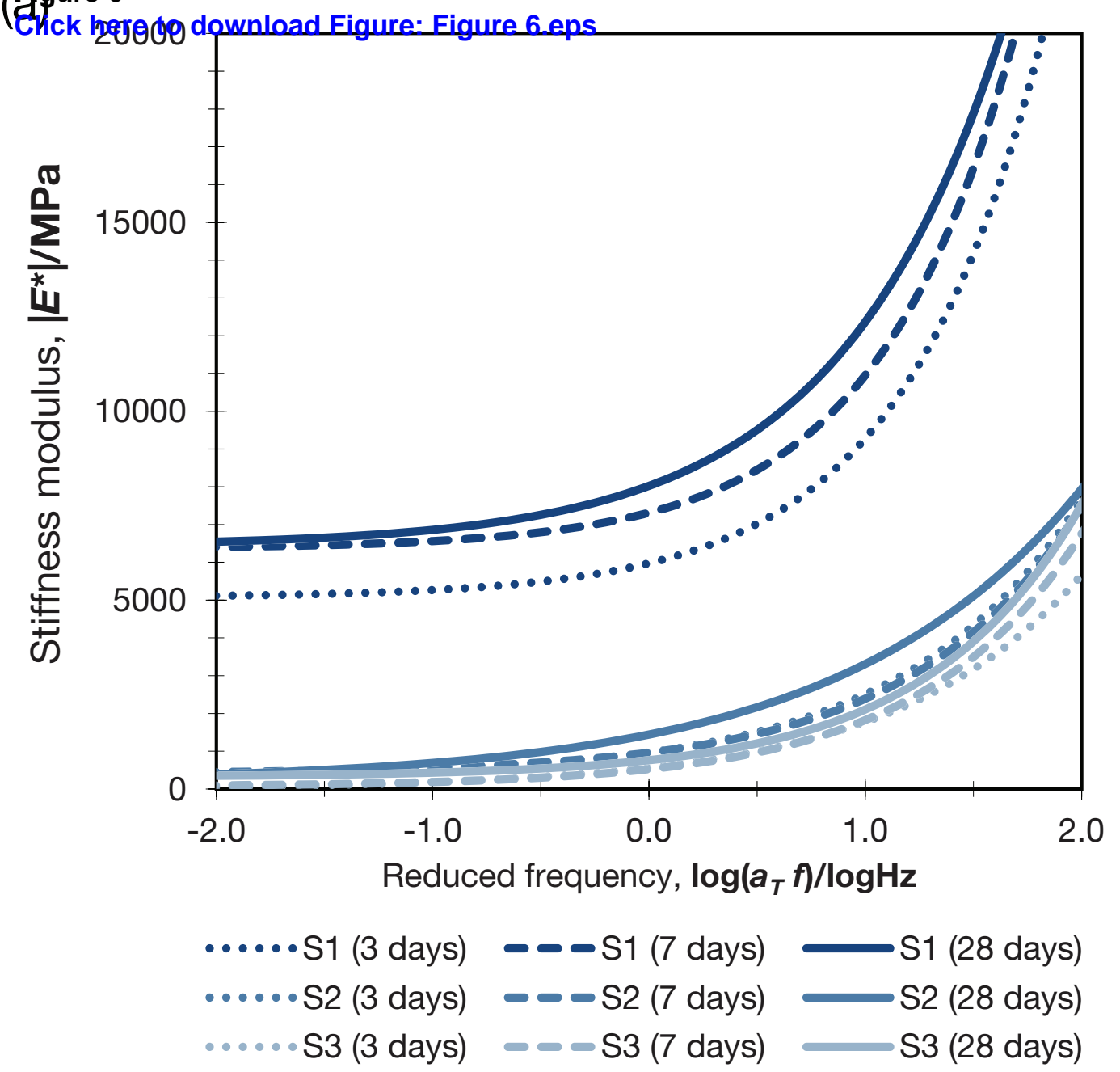

(b)

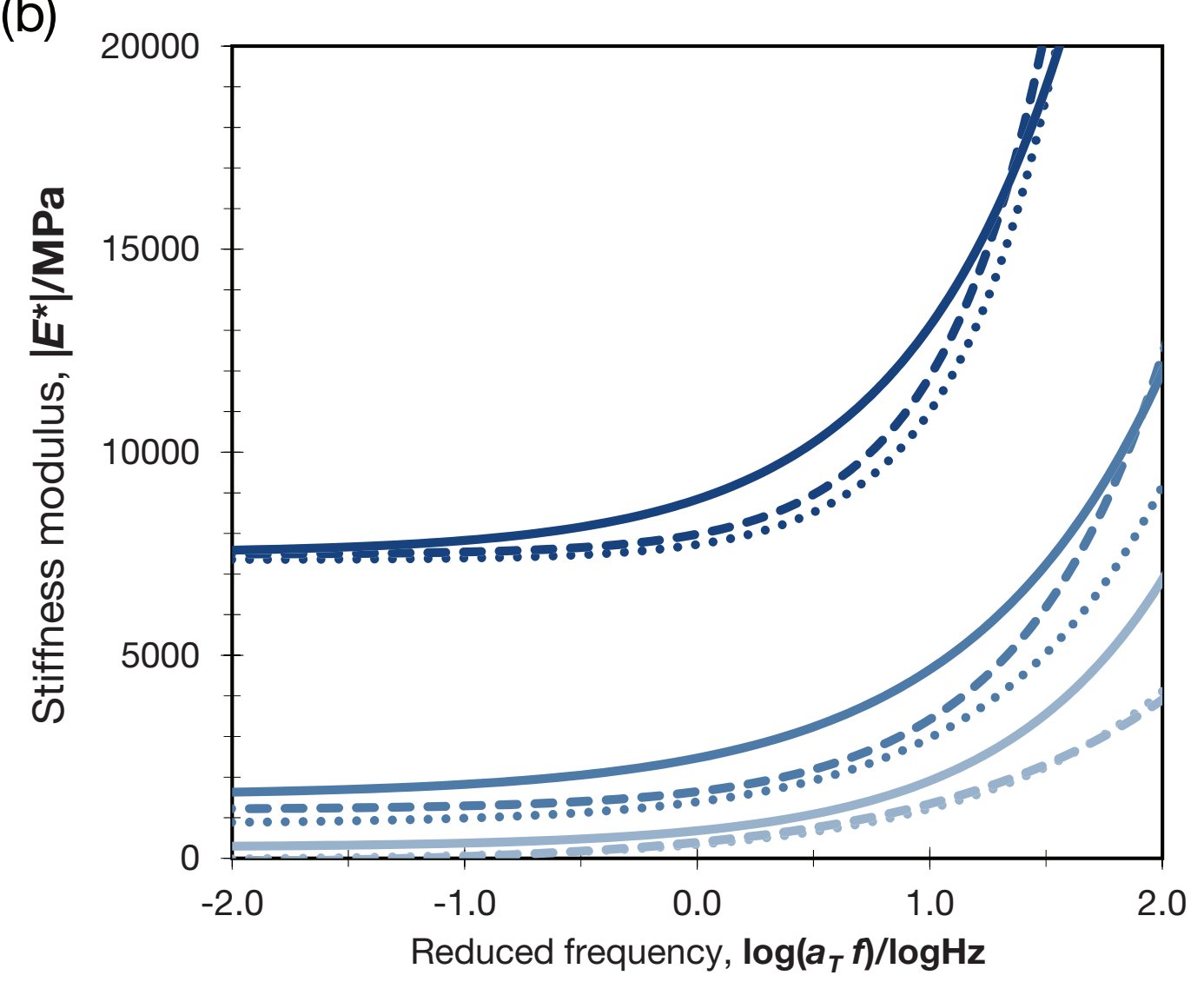

$$
\begin{aligned}
& \text {.....S4 (3 days) - - - S4 (7 days) —S4 (28 days) } \\
& \text {.....S5 (3 days) - - } 55 \text { (7 days) \5 (28 days) } \\
& \ldots . . .56 \text { (3 days) } \quad-- \text { S6 (7 days) —S6 (28 days) }
\end{aligned}
$$




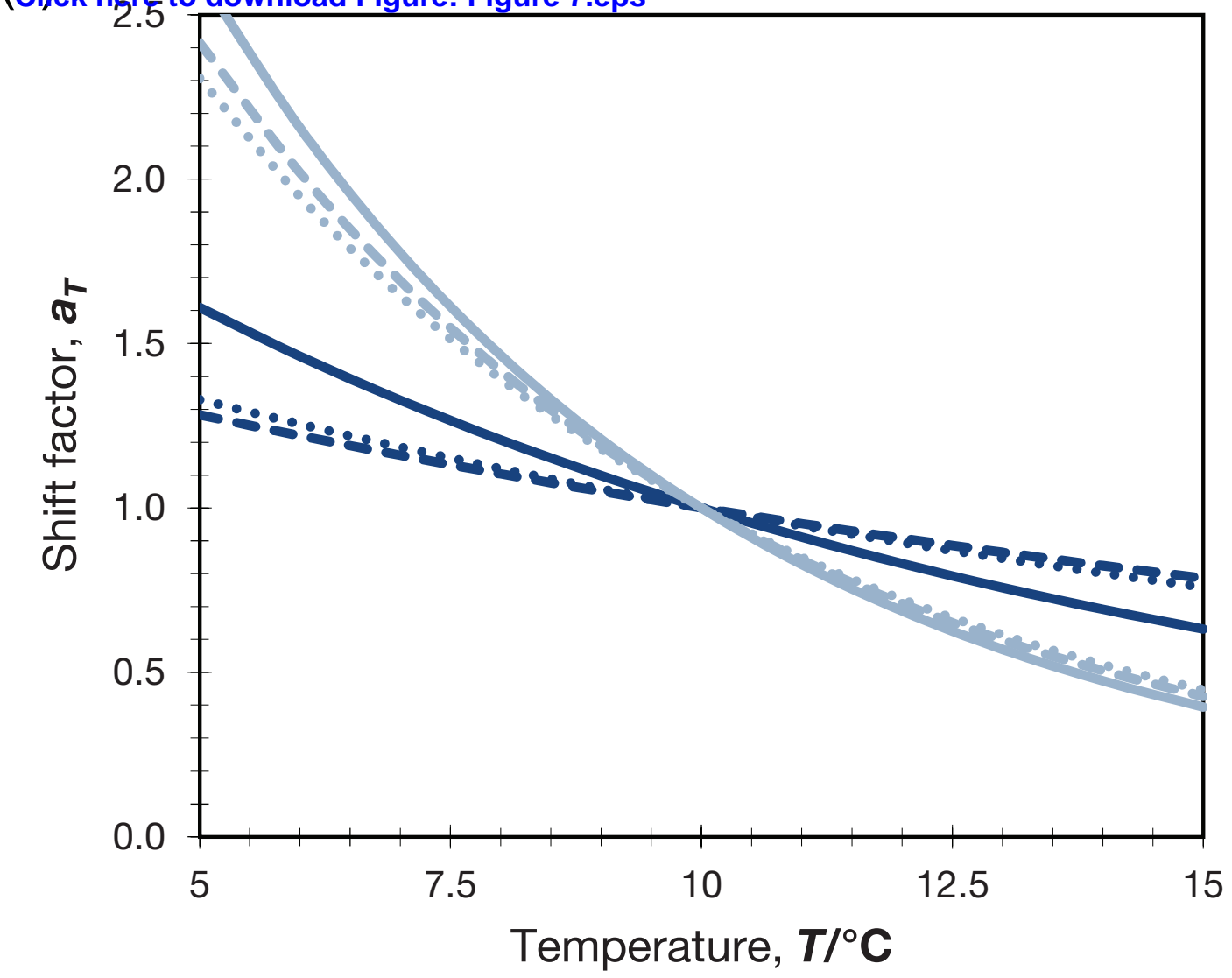

$$
\begin{aligned}
& \text {.....S1 (3 days) - - S1 (7 days) —S1 (28 days) } \\
& \ldots . . . S 3 \text { (3 days) } \quad-\infty \text { S3 (7 days) } \quad \text { S3 (28 days) }
\end{aligned}
$$

(b)

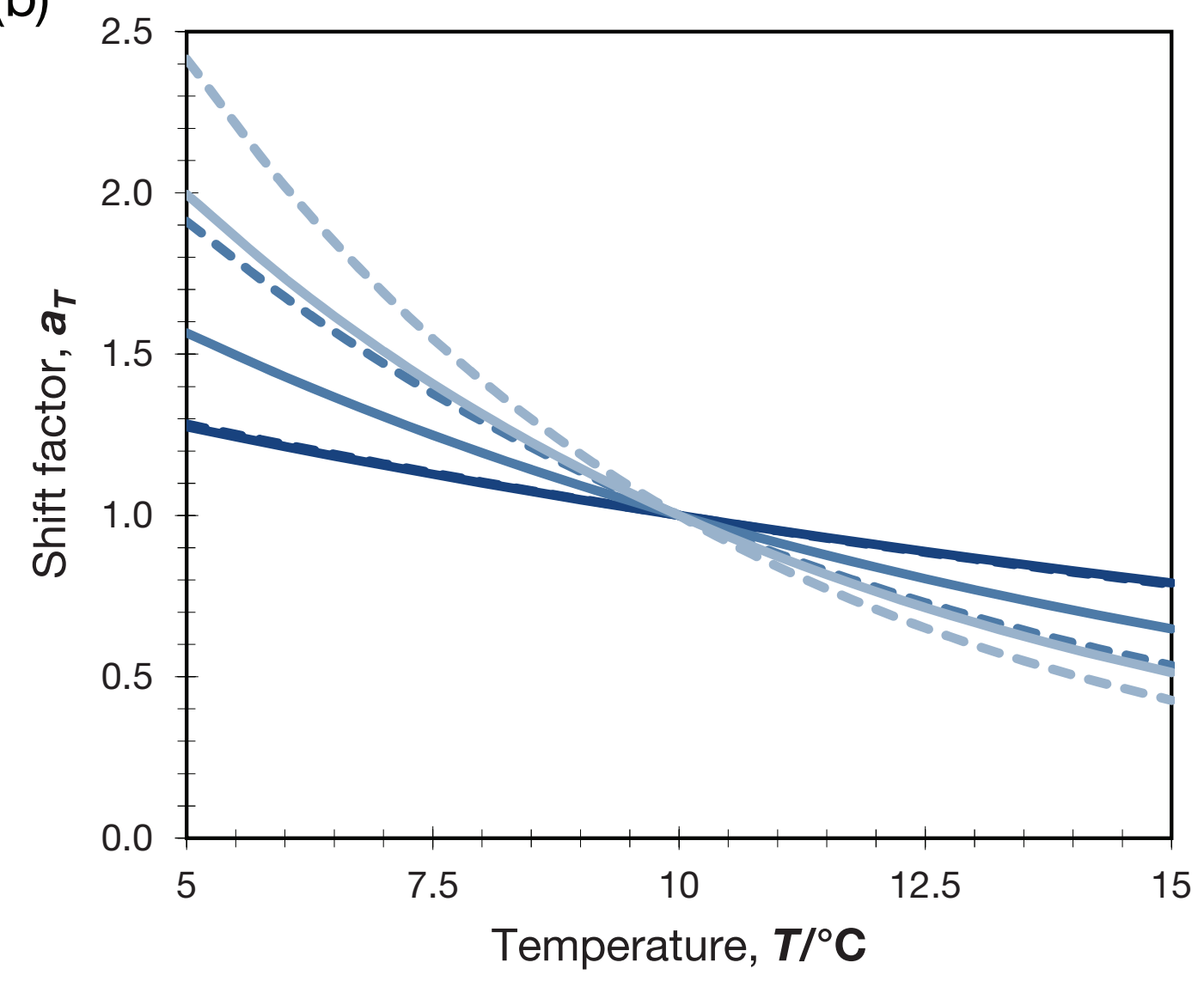

$$
\begin{aligned}
& \text { - }-\mathrm{S} 1 \text { (7 days) }-\infty \mathrm{S} 2 \text { (7 days) }-\infty \mathrm{S} 3 \text { (7 days) } \\
& \text { S4 (7 days) } \quad \text { S5 (7 days) } \quad \text { S6 (7 days) }
\end{aligned}
$$




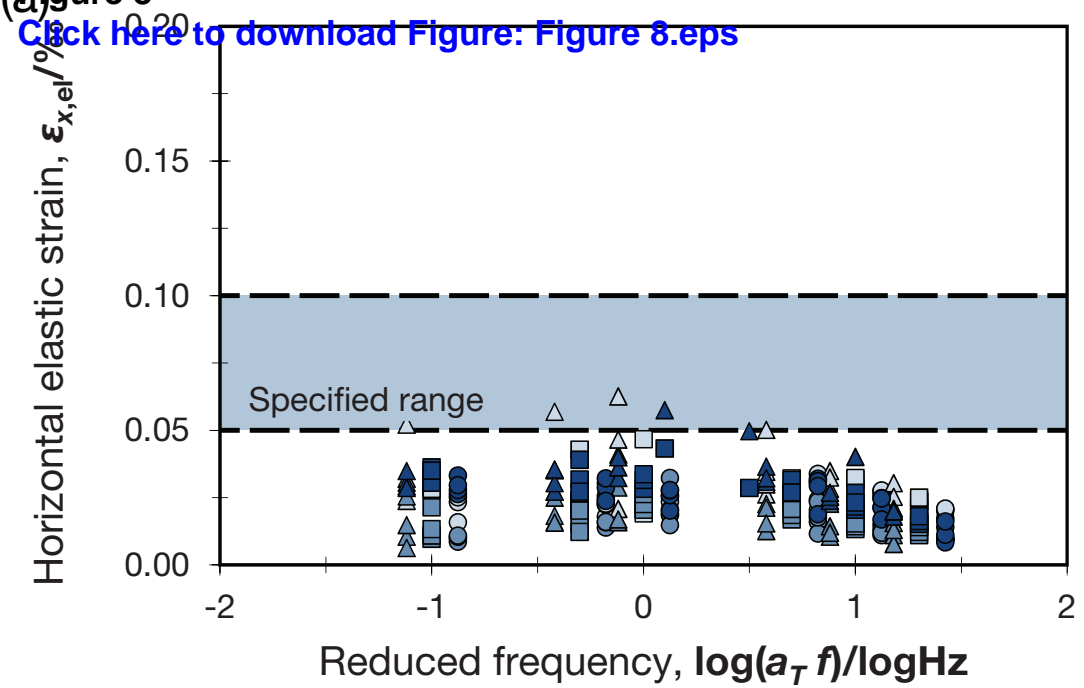

OS1 $\left(3\right.$ days, $\left.5^{\circ} \mathrm{C}\right) \quad \square \mathrm{S} 1\left(3\right.$ days, $\left.10^{\circ} \mathrm{C}\right) \quad \Delta \mathrm{S} 1\left(3\right.$ days, $\left.15^{\circ} \mathrm{C}\right)$

o $S 1\left(7\right.$ days, $\left.5^{\circ} \mathrm{C}\right) \quad \square \mathrm{S} 1\left(7\right.$ days, $\left.10^{\circ} \mathrm{C}\right) \quad \Delta \mathrm{S} 1\left(7\right.$ days, $\left.15^{\circ} \mathrm{C}\right)$

- $\mathrm{S} 1\left(28\right.$ days, $\left.5^{\circ} \mathrm{C}\right) \quad \mathrm{S} 1\left(28\right.$ days, $\left.10^{\circ} \mathrm{C}\right) \Delta \mathrm{S} 1\left(28\right.$ days, $\left.15^{\circ} \mathrm{C}\right)$

(b)

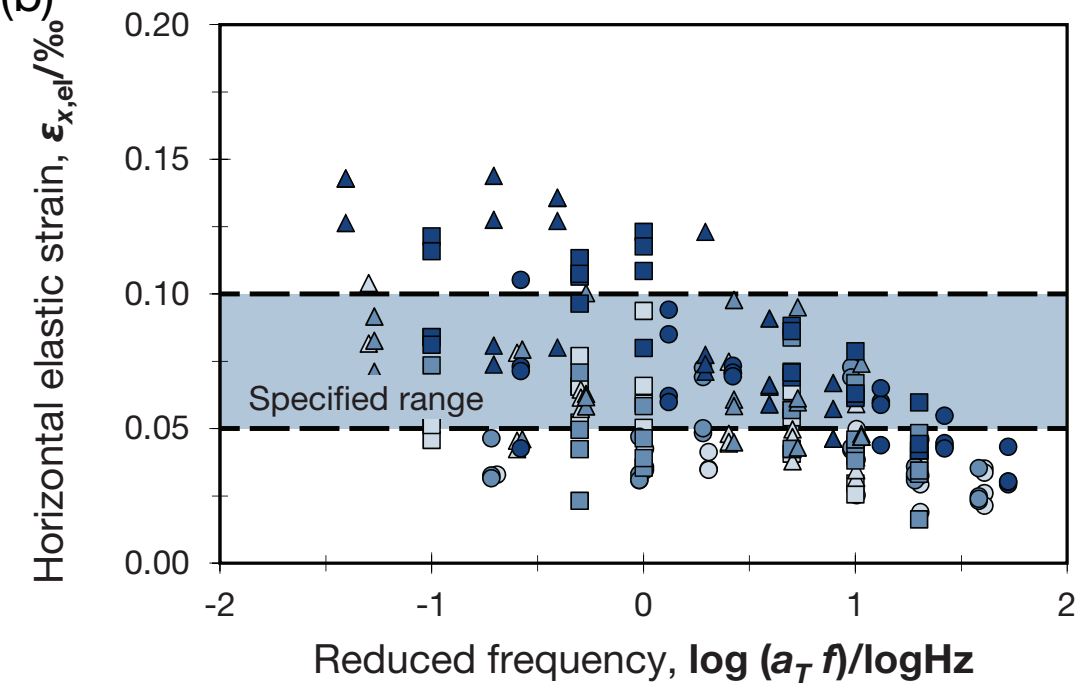

o $2\left(3\right.$ days, $\left.5^{\circ} \mathrm{C}\right) \quad \square \mathrm{S} 2\left(3\right.$ days, $\left.10^{\circ} \mathrm{C}\right) \quad \triangle \mathrm{S} 2\left(3\right.$ days, $\left.15^{\circ} \mathrm{C}\right)$

o $2\left(7\right.$ days, $\left.5^{\circ} \mathrm{C}\right) \quad \square \mathrm{S} 2\left(7\right.$ days, $\left.10^{\circ} \mathrm{C}\right) \quad \Delta \mathrm{S} 2\left(7\right.$ days, $\left.15^{\circ} \mathrm{C}\right)$

o $\mathrm{S} 2\left(28\right.$ days, $\left.5^{\circ} \mathrm{C}\right) \quad \mathrm{S} 2\left(28\right.$ days, $\left.10^{\circ} \mathrm{C}\right) \Delta \mathrm{S} 2\left(28\right.$ days, $\left.15^{\circ} \mathrm{C}\right)$

(c)

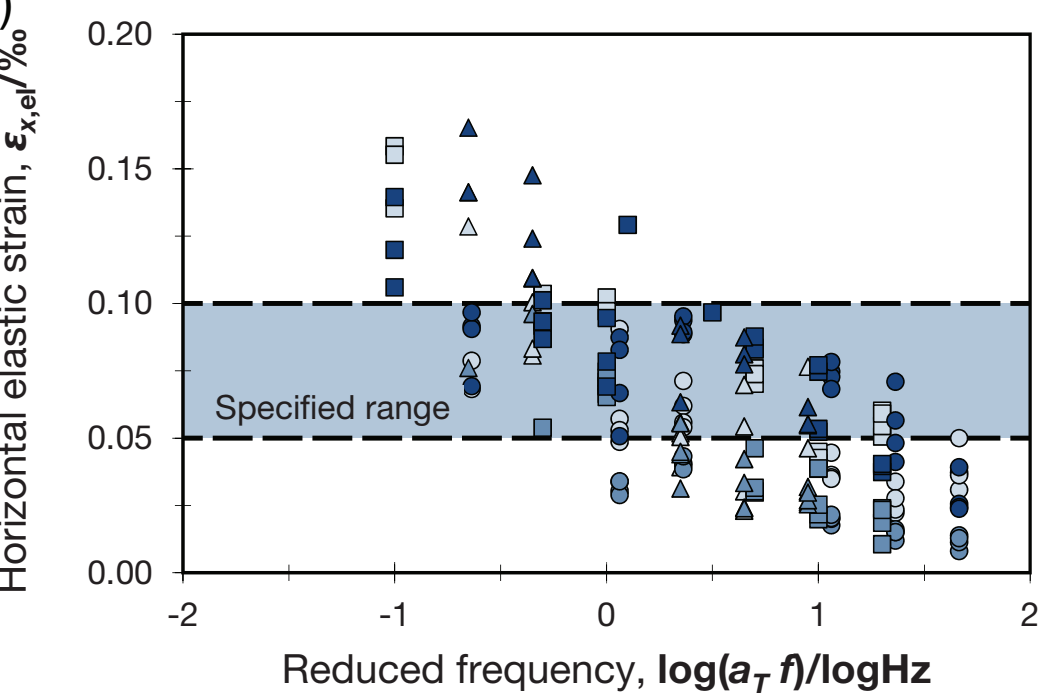

o S3 $\left(3\right.$ days, $\left.5^{\circ} \mathrm{C}\right) \quad \square \mathrm{S} 3\left(3\right.$ days, $\left.10^{\circ} \mathrm{C}\right) \quad \triangle \mathrm{S} 3\left(3\right.$ days, $\left.15^{\circ} \mathrm{C}\right)$

o $33\left(7\right.$ days, $\left.5^{\circ} \mathrm{C}\right) \quad \square \mathrm{S} 3\left(7\right.$ days, $\left.10^{\circ} \mathrm{C}\right) \quad \Delta \mathrm{S} 3\left(7\right.$ days, $\left.15^{\circ} \mathrm{C}\right)$

- $\mathrm{S} 3\left(28\right.$ days, $\left.5^{\circ} \mathrm{C}\right) \quad \square \mathrm{S} 3\left(28\right.$ days, $\left.10^{\circ} \mathrm{C}\right) \Delta \mathrm{S} 3\left(28\right.$ days, $\left.15^{\circ} \mathrm{C}\right)$ 


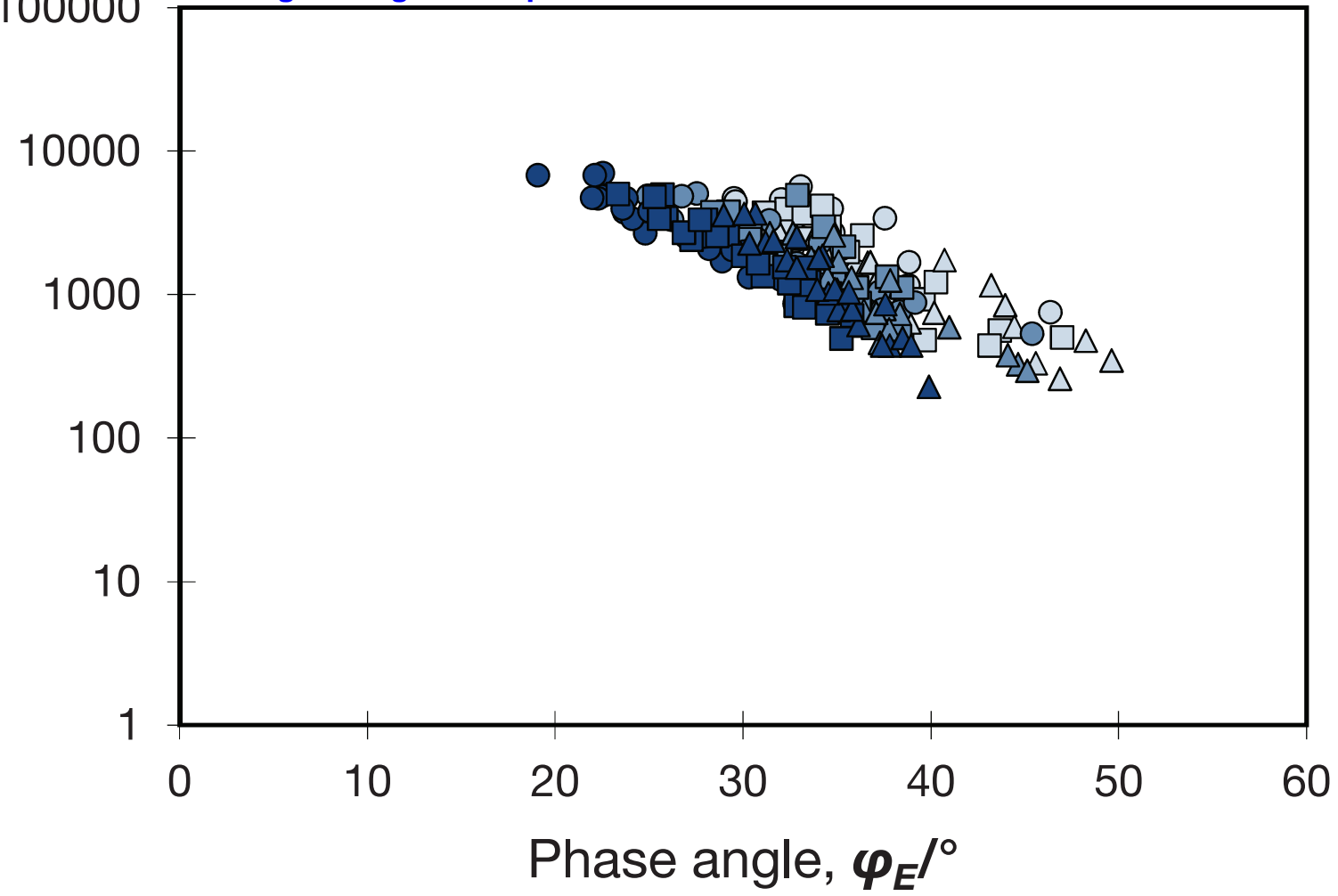

o $\mathrm{S} 2\left(3\right.$ days, $\left.5^{\circ} \mathrm{C}\right) \quad \square \mathrm{S} 2\left(3\right.$ days, $\left.10^{\circ} \mathrm{C}\right) \quad \triangle \mathrm{S} 2\left(3\right.$ days, $\left.15^{\circ} \mathrm{C}\right)$ o $\mathrm{S} 2\left(7\right.$ days, $\left.5^{\circ} \mathrm{C}\right) \quad \square \mathrm{S} 2\left(7\right.$ days, $\left.10^{\circ} \mathrm{C}\right) \quad \Delta \mathrm{S} 2\left(7\right.$ days, $\left.15^{\circ} \mathrm{C}\right)$ - $S 2\left(28\right.$ days, $\left.5^{\circ} \mathrm{C}\right) \quad \square \mathrm{S} 2\left(28\right.$ days, $\left.10^{\circ} \mathrm{C}\right) \Delta \mathrm{S} 2\left(28\right.$ days, $\left.15^{\circ} \mathrm{C}\right)$

(b)

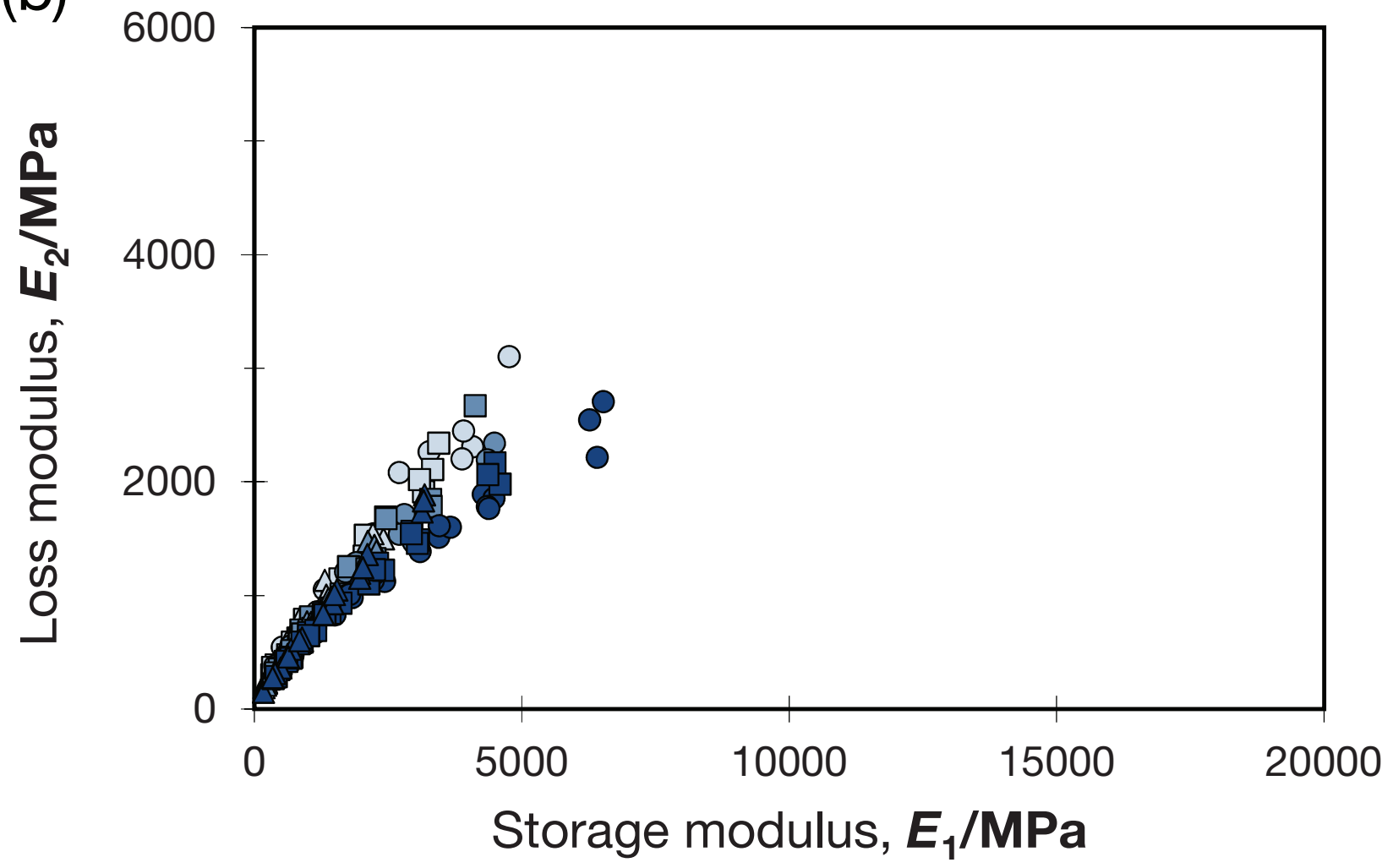

o $S 2\left(3\right.$ days, $\left.5^{\circ} \mathrm{C}\right) \quad \square \mathrm{S} 2\left(3\right.$ days, $\left.10^{\circ} \mathrm{C}\right) \quad \Delta \mathrm{S} 2\left(3\right.$ days, $\left.15^{\circ} \mathrm{C}\right)$ o $S 2\left(7\right.$ days, $\left.5^{\circ} \mathrm{C}\right) \quad \square \mathrm{S} 2\left(7\right.$ days, $\left.10^{\circ} \mathrm{C}\right) \quad \Delta \mathrm{S} 2\left(7\right.$ days, $\left.15^{\circ} \mathrm{C}\right)$ o S2 $\left(28\right.$ days, $\left.5^{\circ} \mathrm{C}\right) \quad \square \mathrm{S} 2\left(28\right.$ days, $\left.10^{\circ} \mathrm{C}\right) \quad \Delta \mathrm{S} 2\left(28\right.$ days, $\left.15^{\circ} \mathrm{C}\right)$ 


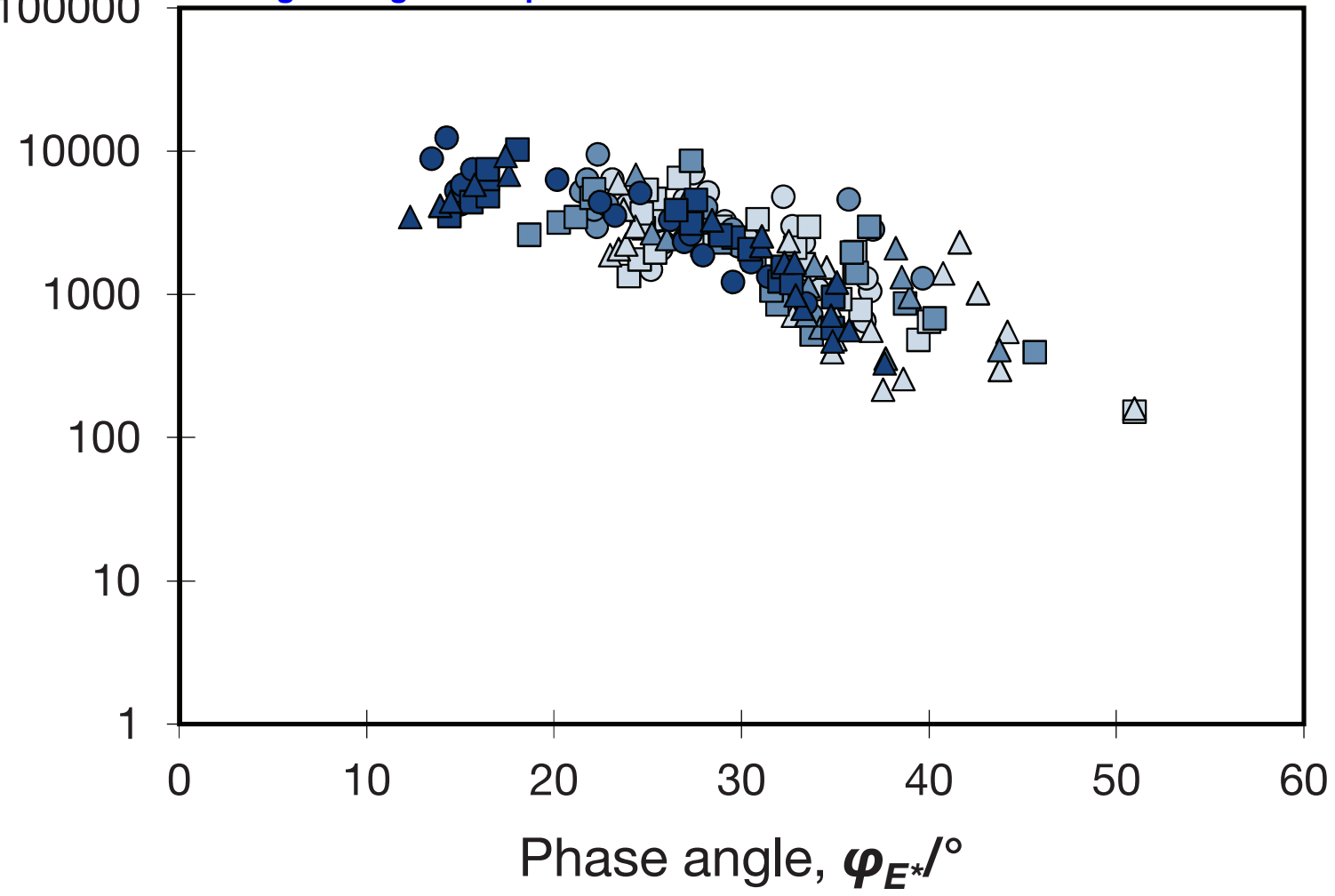

O $55\left(3\right.$ days, $\left.5^{\circ} \mathrm{C}\right) \quad \square \mathrm{S} 5\left(3\right.$ days, $\left.10^{\circ} \mathrm{C}\right) \quad \triangle \mathrm{S} 5\left(3\right.$ days, $\left.15^{\circ} \mathrm{C}\right)$ o $55\left(7\right.$ days, $\left.5^{\circ} \mathrm{C}\right) \quad \square \mathrm{S} 5\left(7\right.$ days, $\left.10^{\circ} \mathrm{C}\right) \quad \Delta \mathrm{S} 5\left(7\right.$ days, $\left.15^{\circ} \mathrm{C}\right)$ - $S 5\left(28\right.$ days, $\left.5^{\circ} \mathrm{C}\right) \quad \square \mathrm{S} 5\left(28\right.$ days, $\left.10^{\circ} \mathrm{C}\right) \quad \Delta \mathrm{S} 5\left(28\right.$ days, $\left.15^{\circ} \mathrm{C}\right)$

(b)

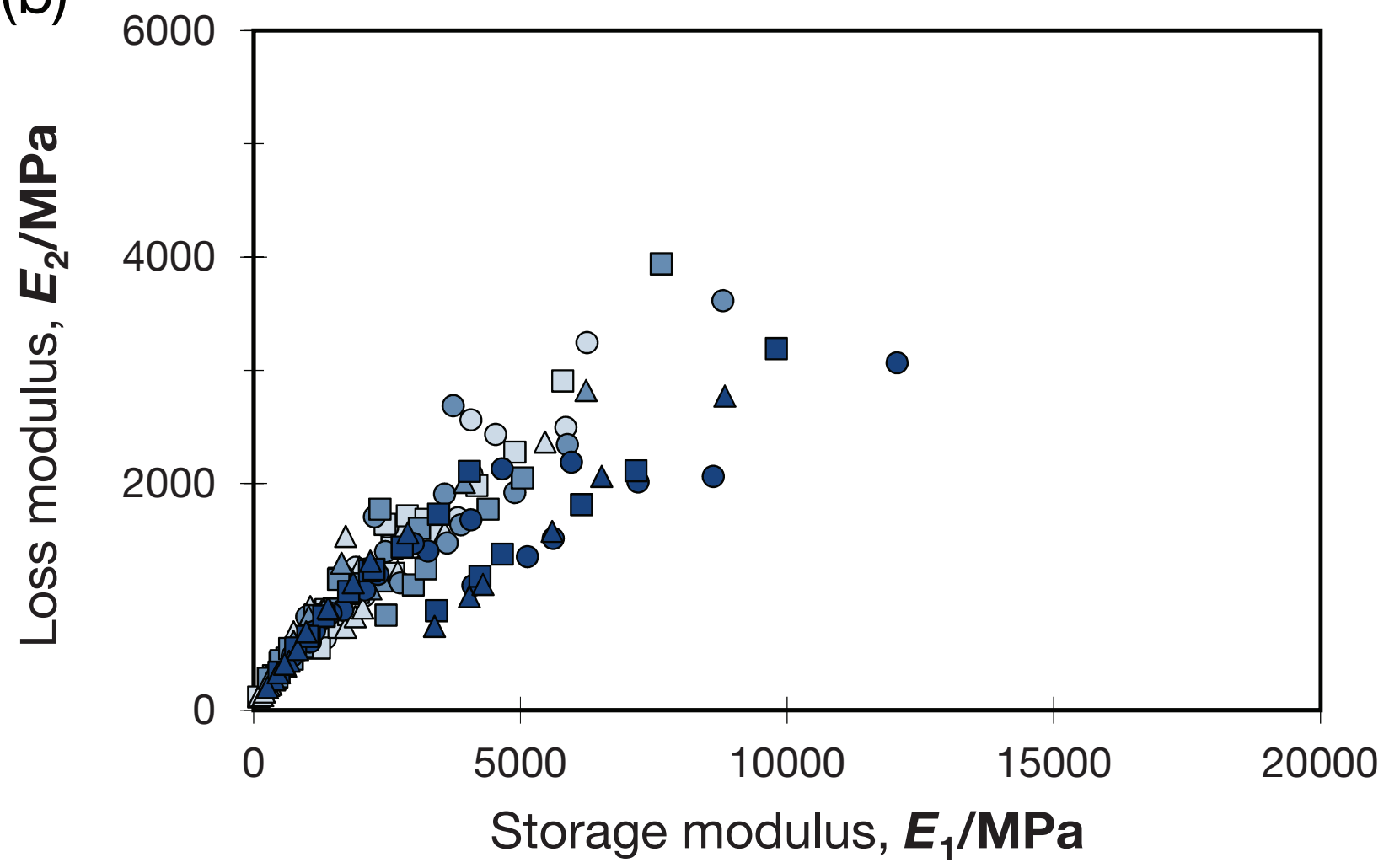

O $55\left(3\right.$ days, $\left.5^{\circ} \mathrm{C}\right) \quad \square \mathrm{S} 5\left(3\right.$ days, $\left.10^{\circ} \mathrm{C}\right) \quad \Delta \mathrm{S} 5\left(3\right.$ days, $\left.15^{\circ} \mathrm{C}\right)$ o $55\left(7\right.$ days, $\left.5^{\circ} \mathrm{C}\right) \quad \square \mathrm{S} 5\left(7\right.$ days, $\left.10^{\circ} \mathrm{C}\right) \quad \Delta \mathrm{S} 5\left(7\right.$ days, $\left.15^{\circ} \mathrm{C}\right)$ - $\mathrm{S} 5\left(28\right.$ days, $\left.5^{\circ} \mathrm{C}\right) \quad \square \mathrm{S} 5\left(28\right.$ days, $\left.10^{\circ} \mathrm{C}\right) \quad \Delta \mathrm{S} 5\left(28\right.$ days, $\left.15^{\circ} \mathrm{C}\right)$ 


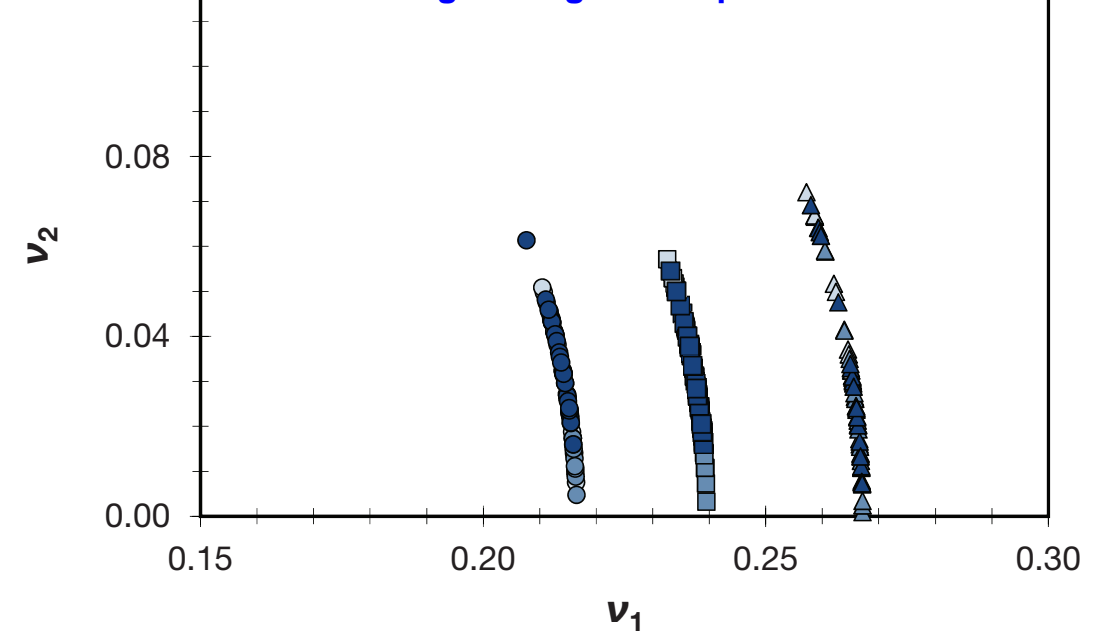

OS1 $\left(3\right.$ days, $\left.5^{\circ} \mathrm{C}\right) \quad \square \mathrm{S} 1\left(3\right.$ days, $\left.10^{\circ} \mathrm{C}\right) \quad \Delta \mathrm{S} 1\left(3\right.$ days, $\left.15^{\circ} \mathrm{C}\right)$

o $S 1\left(7\right.$ days, $\left.5^{\circ} \mathrm{C}\right) \quad \square \mathrm{S} 1\left(7\right.$ days, $\left.10^{\circ} \mathrm{C}\right) \quad \Delta \mathrm{S} 1\left(7\right.$ days, $\left.15^{\circ} \mathrm{C}\right)$

- $\mathrm{S} 1\left(28\right.$ days, $\left.5^{\circ} \mathrm{C}\right) \quad \square \mathrm{S} 1\left(28\right.$ days, $\left.10^{\circ} \mathrm{C}\right) \Delta \mathrm{S} 1\left(28\right.$ days, $\left.15^{\circ} \mathrm{C}\right)$

(b)

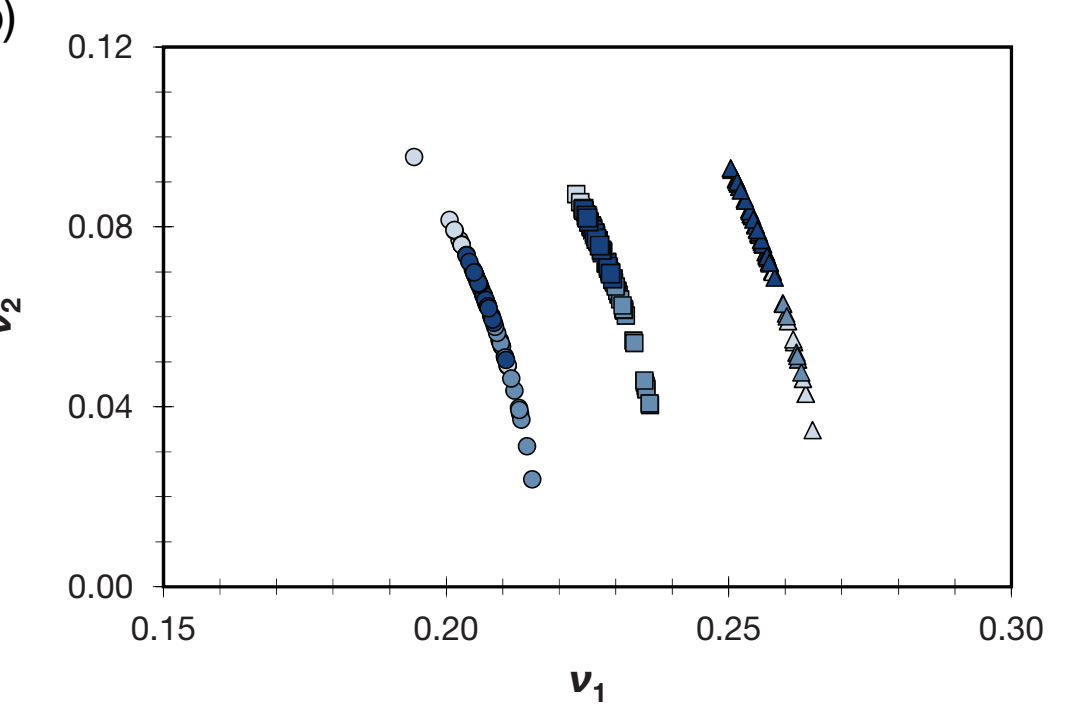

o $2\left(3\right.$ days, $\left.5^{\circ} \mathrm{C}\right) \quad \square \mathrm{S} 2\left(3\right.$ days, $\left.10^{\circ} \mathrm{C}\right) \quad \triangle \mathrm{S} 2\left(3\right.$ days, $\left.15^{\circ} \mathrm{C}\right)$

o $22\left(7\right.$ days, $\left.5^{\circ} \mathrm{C}\right) \quad \square \mathrm{S} 2\left(7\right.$ days, $\left.10^{\circ} \mathrm{C}\right) \quad \Delta \mathrm{S} 2\left(7\right.$ days, $\left.15^{\circ} \mathrm{C}\right)$

- $\mathrm{S} 2\left(28\right.$ days, $\left.5^{\circ} \mathrm{C}\right) \quad$ घS2 $\left(28\right.$ days, $\left.10^{\circ} \mathrm{C}\right) \quad \Delta \mathrm{S} 2\left(28\right.$ days, $\left.15^{\circ} \mathrm{C}\right)$

(c)

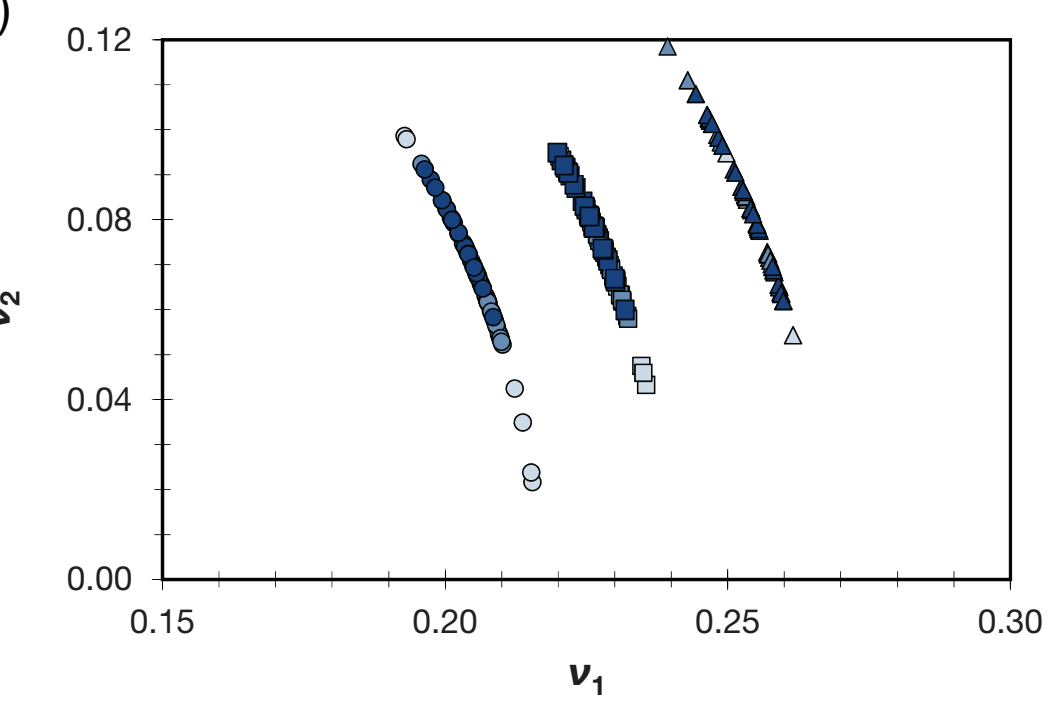

o $33\left(3\right.$ days, $\left.5^{\circ} \mathrm{C}\right) \quad \square \mathrm{S} 3\left(3\right.$ days, $\left.10^{\circ} \mathrm{C}\right) \quad \Delta \mathrm{S} 3\left(3\right.$ days, $\left.15^{\circ} \mathrm{C}\right)$

o $33\left(7\right.$ days, $\left.5^{\circ} \mathrm{C}\right) \quad \square \mathrm{S} 3\left(7\right.$ days, $\left.10^{\circ} \mathrm{C}\right) \quad \Delta \mathrm{S} 3\left(7\right.$ days, $\left.15^{\circ} \mathrm{C}\right)$

- S3 $\left(28\right.$ days, $\left.5^{\circ} \mathrm{C}\right) \quad \square \mathrm{S} 3\left(28\right.$ days, $\left.10^{\circ} \mathrm{C}\right) \quad \Delta \mathrm{S} 3\left(28\right.$ days, $\left.15^{\circ} \mathrm{C}\right)$ 
Figure 17

Click here to download Figure: Figure 17.eps
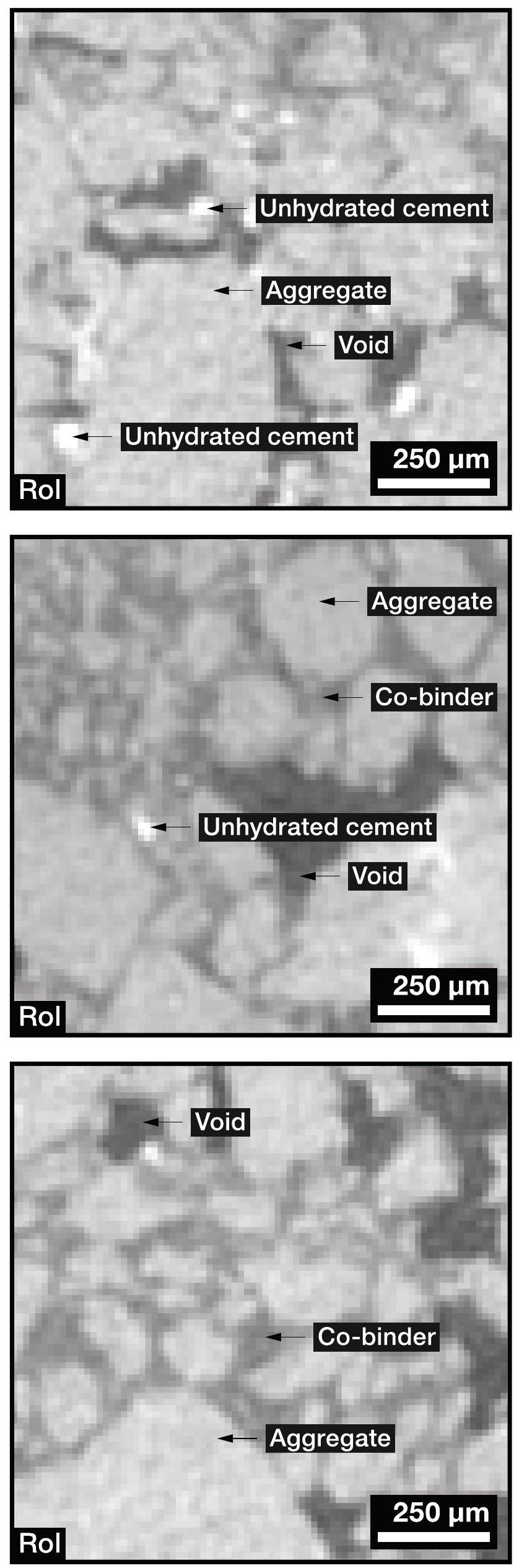

(a)

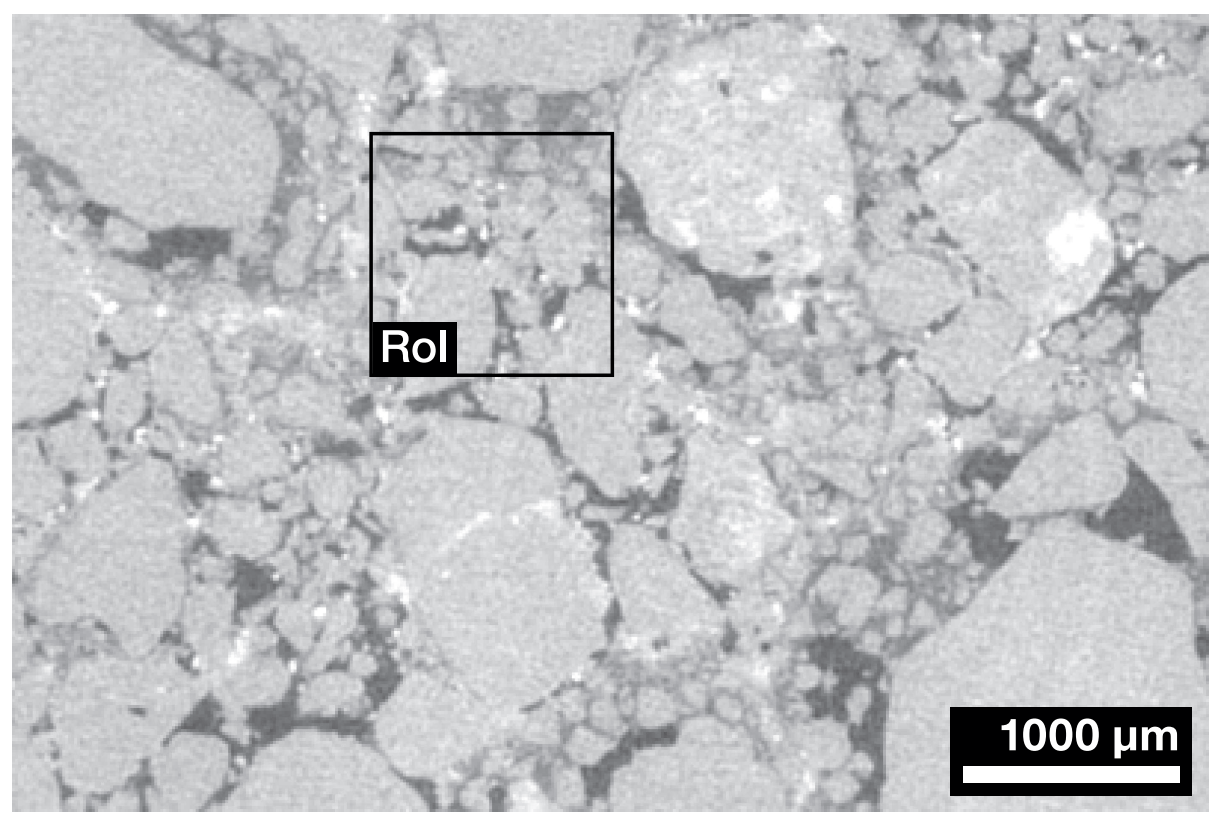

(b)

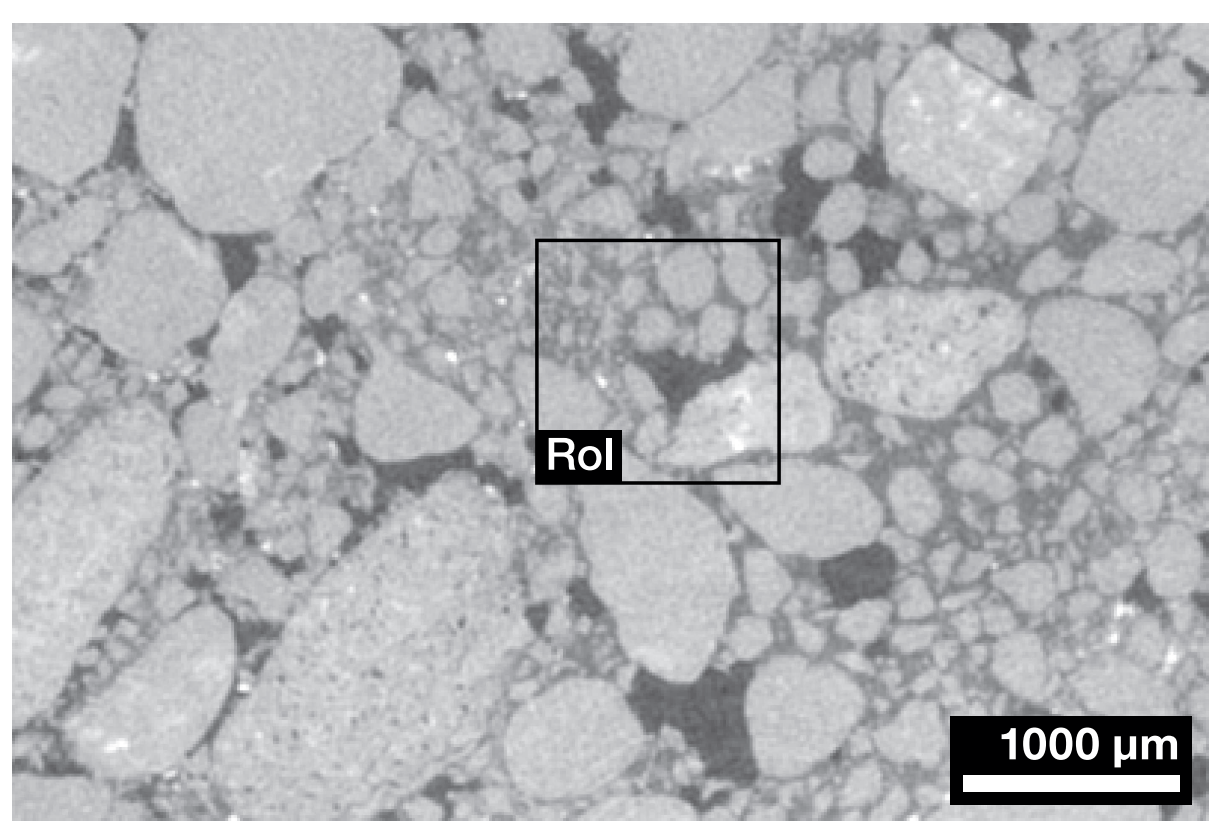

(c)

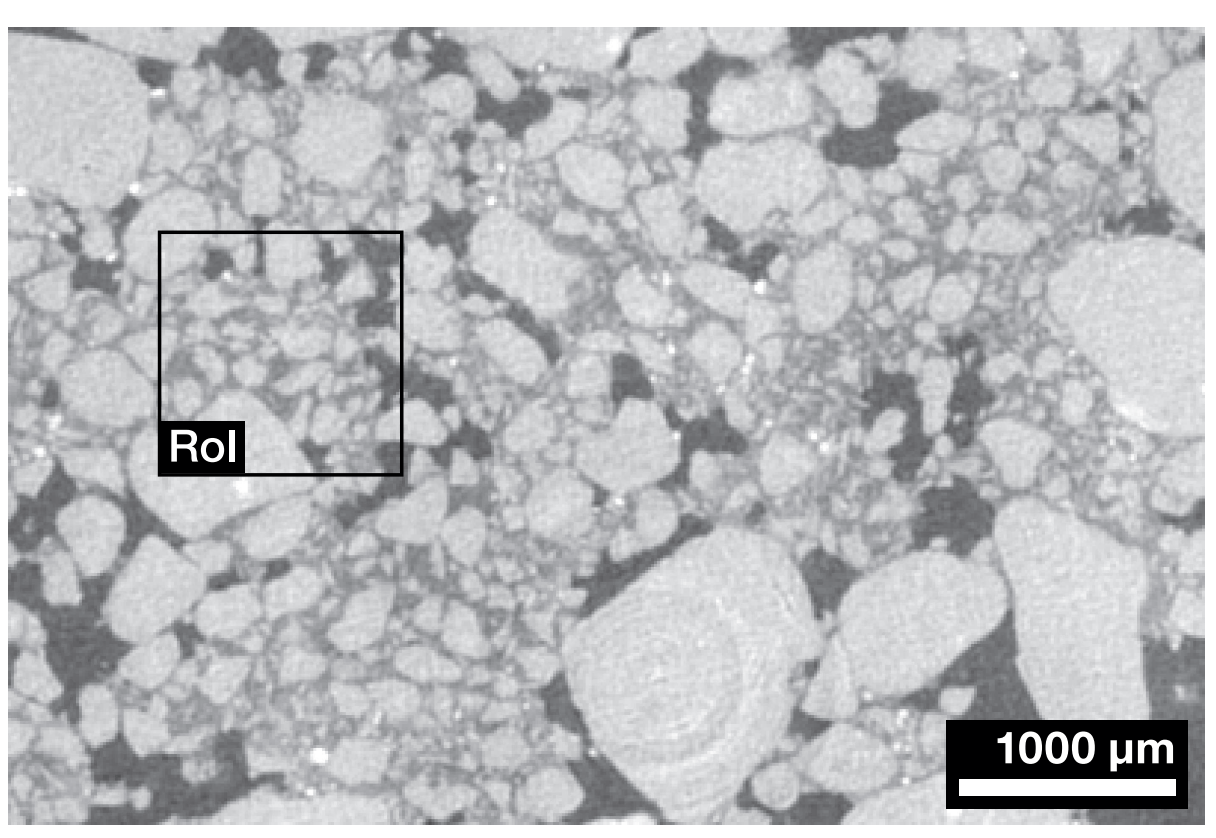

- Void

— Aggregate

$250 \mu \mathrm{m}$ 


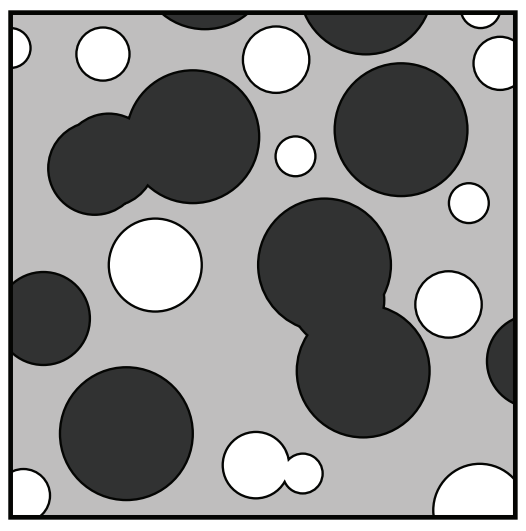

Suspension of the bitumenous phase

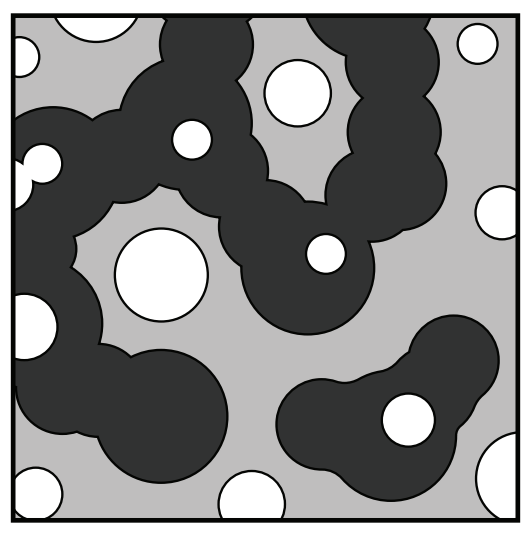

State between the percolation thresholds (general two-phase material)

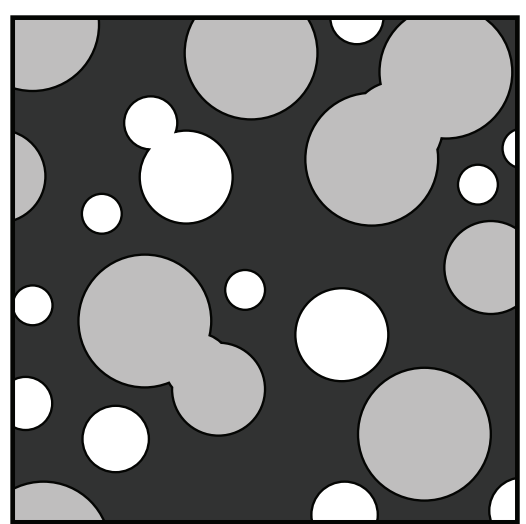

Suspension of the cementitious phase

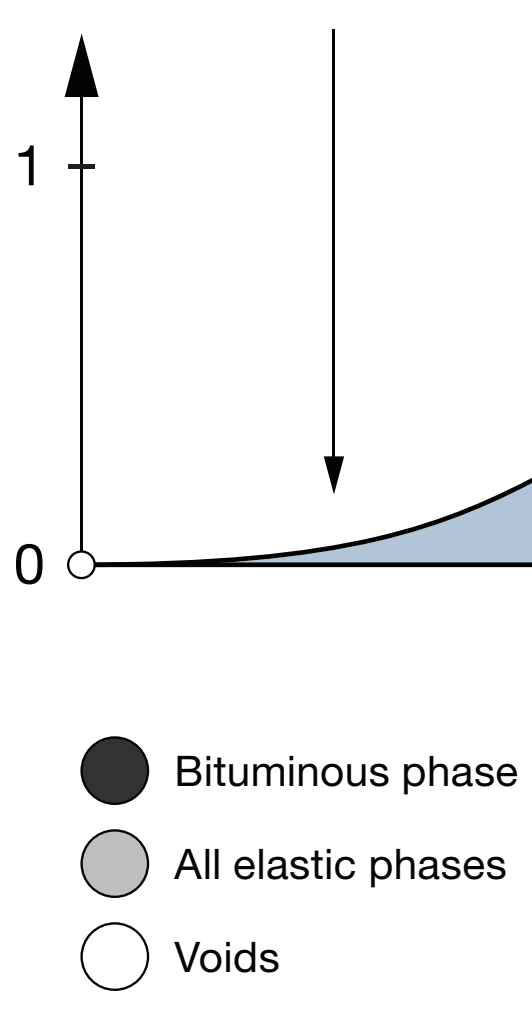

Share of the bitumen-dominated behaviour

Percolation probability of the bituminous phase

(logarithmic scale)

$$
1
$$$$
2
$$$$
4
$$

$b / c$ 

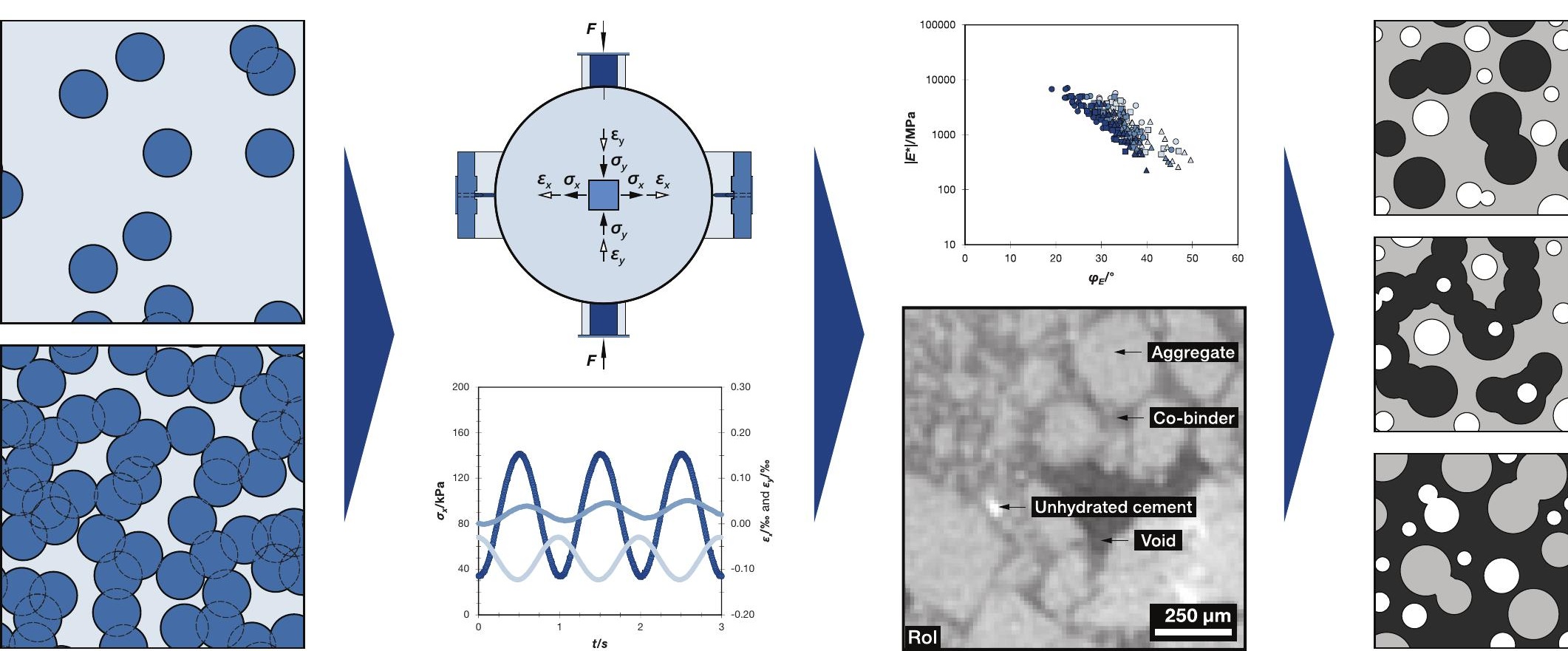